\title{
Las agencias estatales de naturaleza especial en Colombia'
}

\author{
María Clara Garrido²
}

\section{RESUMEN}

Con la más reciente reforma a la estructura de la administración pública colombiana del orden nacional se propaga entre 2011 y 2013 la figura de la "agencia nacional", término con el que se denomina a una serie de organismos administrativos que estarían orientados al logro de resultados y a la eficaz utilización de los recursos públicos. Dentro de las agencias creadas aparecen aquellas "estatales de naturaleza especial" como unidades de servicios de la administración, con las que se pretendía contar con estructuras diferentes, que estuvieran caracterizadas por una especialidad y tecnicidad. A partir de una comparación que abarca aspectos orgánicos y funcionales se buscó determinar si realmente las agencias estatales de naturaleza especial constituyen una tipología de órganos distinta de los organismos y entidades contemplados en la Ley 489 de 1998.

Palabras clave: Agencias estatales, Estructura de la administración pública, Reformas a la administración pública, Organización administrativa.

1 Esta investigación es producto del trabajo realizado en la Maestría de Investigación de Derecho Administrativo de la Universidad Externado de Colombia. El documento que aquí se presenta es una versión ajustada de la primera parte de la investigación, siguiendo los requerimientos de esta Revista.

2 Vicepresidenta administrativa, Agencia Nacional de Infraestructura, Bogotá, Colombia. Maestría en Derecho Administrativo, Universidad Externado de Colombia, Bogotá, Colombia. Especialista en Derecho Financiero, Universidad del Rosario, Bogotá, Colombia. Correo-e:mariagarrido@cable.net.co Fecha de recepción: 10 de octubre de 2016. Fecha de modificación: 10 de noviembre de 2016. Fecha de aceptación: 25 de noviembre de 2016. Para citar el artículo: Garrido, M. C., "Las agencias estatales de naturaleza especial en Colombia", Revista digital de Derecho Administrativo, n. ${ }^{\circ} 17$, primer semestre, Universidad Externado de Colombia, 2017, pp. 243-290. DOI: http://dx.doi.org/10.18601/21452946. n17.13 


\title{
State Agencies of Special Nature in Colombia
}

\author{
ABSTRACT
}

With the latest reform of the Colombian Public Administration (2011 to 2013), the use of the term "National Agency" increases, in order to designate new administrative structures aimed to produce results and effectively manage public resources. Among the newly created administration, some structures were referred as "state agencies of special nature", due to their alleged technical and specialized character. Through a comparison that encompasses functional and institutional aspects, this paper demonstrates that the expression "state agencies of special nature" does not establish a new category of public entities, different from other national agencies and administrative bodies listed in Act 489 of 1998.

Keywords: State Agencies, Public Administration, Institutional Reforms, Administrative Organization, National Agencies.

\section{INTRODUCCIÓN}

El tema a que se refirió la investigación se expondrá en dos publicaciones. El objeto de esta primera entrega consiste en determinar si las agencias nacionales de naturaleza especial son en derecho colombiano instituciones que conducen hacia un tipo nuevo de organización, es decir, si con esa expresión se alude a una categoría de órganos administrativos con características sustanciales que permitan distinguirlos de las categorías de estructuras tradicionales de la administración pública del orden nacional, o si esta corresponde a un término genérico, similar al que existe en el derecho comparado.

Al efecto, dado el tema sobre el cual versa el número de la revista en que se publicará este trabajo, y teniendo como premisa "que el concepto de infraestructura pública hace referencia a la existencia de una red organizada para la prestación del servicio público, conformada tanto por obras públicas como por servicios materiales adicionales asociados a dichas obras y necesarios para una adecuada prestación del servicio público"3, debe hacerse notar que dentro del tipo de agencias fruto de la reforma a la administración pública nacional arriba mencionada, se concibió a la Agencia Nacional de Infraestructura, como una agencia nacional estatal de naturaleza especial, del sector descentralizado

3 JuAn C. Expósito y Jorge E. SAntos. "La iniciativa privada en las concesiones de infraestructura y servicios públicos", Revista Digital de Derecho Administrativo n. ${ }^{\circ} 3$, segundo semestre, Universidad Externado de Colombia, 2009, pp. 81-150, disponible en: http://revistas. uexternado.edu.co/index.php/Deradm/article/download/2573/2215 
de la rama ejecutiva del orden nacional, con personería jurídica, patrimonio propio y autonomía administrativa, financiera y técnica, adscrita al Ministerio de Transporte, a la cual se le encomendó:

... planear, coordinar, estructurar, contratar, ejecutar, administrar y evaluar proyectos de concesiones y otras formas de Asociación Público Privada (APP), para el diseño, construcción, mantenimiento, operación, administración y/o explotación de la infraestructura pública de transporte en todos sus modos y de los servicios conexos o relacionados y el desarrollo de proyectos de asociación público privada para otro tipo de infraestructura pública cuando así lo determine expresamente el Gobierno Nacional respecto de infraestructuras semejantes a las enunciadas en este artículo, dentro del respeto a las normas que regulan la distribución de funciones y competencias y su asignación.

Esta Agencia ha sido reconocida por la publicación inglesa $P_{3}$ Bulletin como la mejor agencia gubernamental de 2014 de asociaciones público privadas (APP), por su liderazgo y eficiencia en incentivar la participación privada en la construcción de proyectos de infraestructura para los ciudadanos ${ }^{4}$.

Esta primera entrega culmina con unas consideraciones finales, y en una segunda se presentará lo relativo a si las agencias de naturaleza especial como entidades de la administración pública poseen atributos de los órganos descentralizados de la rama ejecutiva del poder público, identificando cuál es su naturaleza jurídica, una vez demostrada la verdadera noción de este tipo de agencias, en el derecho público colombiano.

En términos generales, las reformas en materia de organización buscan racionalizar el aparato administrativo, para adecuarlo a planes y programas de desarrollo económico y social y, de manera general, para dar cumplimiento a los fines estatales ${ }^{5}$. Ciertos autores señalan que muchas características que

4 Disponible en: http://www.ani.gov.co/article/ani-la-mejor-agencia-gubernamental-deasociaciones-público-privadas-en-america.en-2014-13822

5 Se trata de fortalecer la capacidad de los organismos y entidades administrativas, para atender los cometidos a su cargo, permitiendo el cumplimiento de sus objetivos esenciales y la búsqueda del bienestar colectivo. Frente a la organización del Estado, en Colombia la Ley 19 de 1958 se encargó de fijar el alcance del concepto de reforma en materia administrativa al definir en su artículo $1 .^{\circ}$ que la reorganización de la administración pública tiene por objeto "asegurar mejor la coordinación y la continuidad de la acción oficial, conforme a planes de desarrollo progresivo establecidos o que se establezcan por la ley [...] la simplificación y economía en los trámites y procedimientos; evitar la duplicidad de funciones paralelas, y propiciar el ejercicio de un adecuado control administrativo". En concordancia con lo anterior, el artículo 150, numeral 7, de la Constitución Política señala que le corresponde al Congreso de la República: "Determinar la estructura de la administración nacional y crear, suprimir o fusionar ministerios, departamentos administrativos, superintendencias, establecimientos públicos y otras entidades del orden nacional señalando sus objetivos y estructura orgánica; reglamentar la creación y funcionamiento de las Corporaciones Autónomas Regionales dentro de un régimen de autonomía ${ }_{i}$ así mis- 
ha adquirido la administración pública están asociadas al modelo de Estado. Así, para el Estado social de derecho el "breve recorrido histórico demuestra de manera clara, la evidente transformación del fenómeno administrativo y la relación de éste con la evolución de lo 'público' y en concreto de la figura estatal. Esta apreciación resulta obvia si se percibe la administración pública no como una creación de alguien o de un momento determinado, sino como una necesidad social de establecer unas pautas, identificar unas necesidades y ponerlas en acción, con el propósito de alcanzar unos fines" ${ }^{16}$. En este orden de ideas, la crisis de legitimidad política en la década de los ochenta y noventa, a causa de los bajos logros obtenidos por la administración pública en materia de atención de las necesidades de la población, junto con el problema de captura del Estado por el clientelismo y la corrupción ${ }^{7}$, obligó a los Estados nacionales a considerar propuestas de reformas a la administración pública, en aras de mejorar la eficiencia y el equilibrio fiscal ${ }^{8}$. Además, la lucha contra el

mo, crear o autorizar la constitución de empresas industriales y comerciales del Estado y sociedades de economía mixta"; empero, con la participación activa del Gobierno Nacional, de acuerdo con lo señalado en el inciso segundo del artículo 154 de la Constitución. Esta disposición establece la necesidad de contar con la iniciativa del Gobierno, so pena de incurrir en vicios de forma. Además de lo anterior, es posible consultar las sentencias C-401 de 2001, C-736 de 2007 y C-910 de 2007. Documento CONPES 3248, 20 de octubre de 2003.

6 Alberto Montaña. Fundamentos de derecho administrativo, Bogotá: Universidad Externado de Colombia, 2010, p. 83.

7 La falta de efectividad de la administración pública "afecta, también, la legitimidad del Estado, puesto que este es percibido como incapaz para proveer a los colombianos de adecuados servicios públicos en materias que van desde acueducto y alcantarillado hasta administración de justicia": LUIS JAVIER ORJuela. "El Estado colombiano en los noventa: entre la legitimidad y la eficiencia", Revista de Estudios Sociales, Universidad de los Andes (en línea), pp. 56-60, [Consulta 25/02/2016], disponible en: http://res.uniandes.edu.co/ view.php/28/index.php?id

8 Esta situación no fue ajena a América Latina, en donde "La insatisfacción general con el statu quo administrativo se hizo patente en la década de los ochenta, cuando la gente empezó a ver que los estados administradores, en cualquiera de sus tipos, eran incapaces de responder adecuadamente a las transformaciones que en todo el mundo estaban experimentando los mercados, la capacidad fiscal, la tecnología, la política y las actitudes de la población": María del Carmen PARDo, comp., De la Administración Pública a la Gobernanza, Reforma a la Gestión Pública: tendencias y perspectivas, Laurence e. Lynn, JR, pp. 106 a 107. [Consulta 26/02/2016], disponible en: http://www.iapqroo.org.mx/website/biblioteca/ DE\%20LA\% 20ADMINISTRACION\%20PUbLica\%20A\%20LA\%20GobernanZA.pdf Según Gerald Caiden, citado ibídem, "los sistemas administrativos heredados del pasado estaban dando muestra de torpeza, rigidez e insensibilidad ante los cambios en las necesidades humanas y las nuevas circunstancias". Más adelante diría: "los grupos de interés del statu quo y agentes del Estado se habían dedicado a proteger su parcela. Muchos de ellos se habían vuelto ciegos a la posibilidad de que existieran otros tipos de esquemas y no podían concebir que las cosas se hicieran de manera diferente. La complacencia sentó sus reales, hasta que un golpe muy duro -una emergencia súbita, un nuevo invento, un accidente grave la incapacidad ante la presión creciente- hizo que la gente empezara a pensar que algo tenía que hacerse, algo radical, no gradual, una reinvención, no una mera reforma 
aumento de la pobreza y la baja competitividad económica originó la necesidad de reformar el aparato estatal con el fin de cumplir con sus fines esenciales y garantizar los derechos fundamentales ${ }^{9}$.

Desde esta perspectiva, Colombia no ha sido ajena a las reformas a la organización administrativa y se ha interesado en los trabajos y construcciones intelectuales alrededor de las nuevas formas de gobernanza ${ }^{10}$, la mejora en las relaciones entre los ciudadanos y la administración ${ }^{11}$, y estrategias de administración y buen gobierno, con el fin de lograr una mayor eficiencia en la atención de las necesidades de los ciudadanos. Para el efecto, han jugado un papel preponderante las actividades del Centro Latinoamericano de Administración y Desarrollo (CLAD), que durante los últimos años han contribuido al debate de las transformaciones del Estado y de las políticas públicas, procurando aprender de las experiencias recientes de otros países con sus reformas administrativas $^{12}$. En sus conclusiones, el CLAD afirma que la experiencia de los diferentes Estados de América Latina frente a la diversidad de problemáticas sociales y económicas parece haber desplazado la tendencia de reformas simplistas y el

parcial. El derrumbe de la Unión Soviética y de Yugoslavia y el surgimiento de la Unión Europea dieron lugar a varios 'estados de transición' importantes, que buscaban adaptarse a los cambios económicos y políticos regionales por los que atravesaba el mundo entero. América Latina ha participado de lleno en este movimiento internacional, como lo atestiguan las actividades del Centro Latinoamericano de Administración para el Desarrollo (CLAD)".

9 Cfr. Luiz Carlos Bresser Pereira. "La reforma del Estado de los años noventa: lógica y mecanismos de control", en Desarrollo Económico - Revista de Ciencias Sociales, Buenos Aires, vol. 38, n. ${ }^{\circ} 150$, julio-septiembre, 1998, pp. 517-550, disponible en: http://pendientedemigracion.ucm.es/centros/cont/descargas/documento24210.pdf.

Luiz Carlos Bresser Pereira. Lecturas sobre el Estado y las políticas públicas: retomando el debate de ayer para fortalecer el actual, Buenos Aires: CLAD, pp. 259-294, (208).

10 Eduardo Córdova, Fernando Mayorga et al. Gobernabilidad y Gobernanza en América Latina, 2007, [Consulta 25/02/2016], disponible en: http://www.institut-gouvernance.org/docs/ ficha-gobernabilidad.pdf Claire LaUnAY Gama et al., El uso del concepto de gobernanza o/y gobernabilidad en Colombia. Cuaderno Usos y desafíos del concepto de gobernanza en Colombia, Instituto de Investigación y debate sobre la gobernanza, 2006, [Consulta 25/02/2016], disponible en: http://www.institut-gouvernance.org/es/analyse/fiche-analyse-236.html PARDO, ob. cit., 4, pp. 16 y 17.

11 Preocupación presente en sistemas como el francés desde la década de 1970. JEAN BERNARD Auby, "Droit administratif et democratie", en Regulation économique et démocratie, dir. Martine Lombard, Paris: Dalloz, 2006, p. 19.

12 Según lo expuesto por Andrés Palacios Lleras, cabe sostener que si bien las experiencias de otros países en esta materia pueden resultar útiles, en todo caso, el estudio de las condiciones sociales y políticas propias es "particularmente relevante para el derecho administrativo por razones más o menos obvias; esta rama del derecho trata explícitamente sobre las relaciones entre el Estado y los ciudadanos, y los conflictos que surgen entre ellos": "Introducción al Análisis Económico del Derecho Administrativo", Revista de Derecho Público, Universidad de Los Andes, n. ${ }^{\circ} 22$, febrero, 2009, [Consulta 11/05/2016], disponible en https://derechopublico.uniandes.edu.co/components/com_revista/archivos/derechopub/ pub101.pdf. 
recetario técnico de experiencias internacionales, hacia propuestas integrales y diversas, que buscan aumentar las alternativas de intervención pública en la realización del bienestar colectivo ${ }^{13}$. En este sentido el CLAD considera que en el proceso de reconstrucción de los Estados en Latinoamérica "el mayor desafío está en compatibilizar las tendencias mundiales del cambio con las especificidades de la región", a través de una "reforma gerencial" que trascienda "la reforma burocrática weberiana"14. Para el efecto, en el caso colombiano la doctrina se ha referido a las diferentes reformas a la administración pública, como un medio para consolidar la democracia y el desarrollo económico, y para aumentar la capacidad de respuesta del aparato estatal en el logro de los fines esenciales del Estado ${ }^{15}$.

Acerca de las reformas a la organización administrativa en Colombia, se encontraron producciones académicas que abarcan desde aquella llevada a cabo en $1968^{[16]}$ hasta la última producida entre los años 2011 a 2013. De estas se destaca la obra de Diego Younes Moreno, quien se refiere a las reformas del Estado y de la administración pública realizadas desde la presidencia de Lleras Restrepo, hasta la reciente modificación de la organización administrativa durante el actual gobierno; tomando como base la evolución normativa $y$ fuentes jurisprudenciales en materia de estructura ${ }^{17}$. Es sin embargo importante señalar que, en materia de organización administrativa, los estudios que existen se reducen a una descripción, a veces poco detallada, de la estructura

$13 \mathrm{Al}$ respecto, investigadores y científicos sociales se han reunido alrededor del CLAD para proponer debates y reflexiones de las experiencias en Europa y América Latina que puedan mejorar la capacidad del Estado y de las políticas públicas. Tanto la revista Reforma y Democracia, que se viene editando desde el año de 1994, como anualmente los congresos del CLAD, que este año llegan a su XXI versión, representan los espacios de deliberación académica que más influencia ejercen entre los académicos y científicos sociales en América Latina, sin excluir otras revistas de igual importancia de diferentes universidades del continente, como también organismos multilaterales que contribuyen al debate, como el Banco Interamericano de Desarrollo (BID) y la Comisión Económica para América Latina (CEPAL).

14 Consejo Científico del ClaD, Una Nueva Gestión Pública para América Latina, [Consulta 26/02/2016], disponible en http://old.clad.org/investigaciones/investigaciones-concluidas/ documento-del-consejo-cientifico-del-clad-una

15 Jorge EnRIQue IbáÑ̃Ez. "Colombia: un Estado en reforma permanente", Revista Ópera, 2002, pp. 5-21.

16 Jorge Vidal Perdomo. La reforma constitucional de 1968 y sus alcances, Bogotá: Universidad Externado de Colombia, 1970. Al respecto se indica que aun cuando se encontraron producciones académicas sobre esta materia que datan de fechas anteriores a esta obra, para efectos del presente trabajo sólo se consideraron aquellas publicadas a partir de la reforma administrativa de 1968, en las cuales se hace referencia a las formas tradicionales de la administración pública que son las que precisamente se contrastarán con las agencias estatales de naturaleza especial objeto del presente trabajo de investigación.

17 Diego Younes Moreno. Las reformas del Estado y de la Administración Pública, Bogotá: Instituto de Estudios del Ministerio Público, 2012. 
de la administración pública, sin realizar un análisis sobre las razones que motivaron la creación de las instituciones que conforman dicha organización y sus implicaciones desde el punto de vista funcional, o como instrumento para la realización de los fines del Estado ${ }^{18}$. La ausencia de estudios doctrinales críticos de la organización persiste aún, a pesar de las transformaciones registradas por esta desde la expedición de la Constitución Política de 1991.

El nuevo marco constitucional cambiaría radicalmente la configuración del poder público para enfrentar la coyuntura de la época ${ }^{19}$, como también el panorama subsiguiente en la búsqueda de un Estado moderno. En este sentido, Jorge Enrique Ibáñez destaca que los cambios en la estructura de la administración pública obedecen principalmente a las necesidades y aspiraciones del país, para el cumplimiento efectivo de los derechos fundamentales, así como también para ejercer el gobierno y fortalecer la democracia ${ }^{20}$. Después de la promulgación de la Constitución de 1991, que enfatizó en los conceptos de descentralización, desconcentración y delegación como técnicas de organización administrativa, para la recuperación de la gobernabilidad y el logro del acercamiento entre el Estado y los ciudadanos ${ }^{21}$, diferentes gobiernos han acudido a reformar la estructura de la administración pública en Colombia, así:

18 Jorge ENRIQUe IbáÑEZ. Estudios de derecho constitucional y administrativo, Bogotá: Legis y Universidad Sergio Arboleda, 2007; Libardo RodrícueZ, Estructura del poder público en Colombia, Bogotá: Temis, 2015.

19 Estas circunstancias son resumidas por la doctrina de la siguiente manera: "Tres problemas centrales existían en Colombia en el momento en que sale a la luz pública la nueva Carta: crecimiento del narcotráfico con los males que le eran anexos como un aumento de la violencia y de la corrupción, la crisis política, derivada por una parte de un régimen político restrictivo propiciado desde el Frente Nacional, expresado en precarias o casi nulas posibilidades de participación política de otras fuerzas distintas a las del bipartidismo, y por otra, derivada de una gran deslegitimación de la política tradicional en tanto no representaba los intereses del conglomerado social, y finalmente, una intensificación del conflicto armado colombiano entre guerrillas, de un lado, y del otro Estado y grupos paramilitares, que empezaban a obtener gran fuerza. El recrudecimiento de la violencia política durante la década del ochenta había propiciado la violación y limitación de los derechos humanos por parte de los grupos alzados en armas con su accionar y desde el propio Estado con la aplicación de las llamadas prácticas de la guerra sucia y las medidas legales tomadas a partir de la figura del estado de sitio, que como recurso supuestamente excepcional para restablecer el orden público turbado, fue la regla general en Colombia durante gran parte del siglo xx": Universidad de Antioquia, Antecedentes y contexto del surgimiento de la Constitución de 1991, [Consulta 26/02/2016], disponible en: http://docencia.udea. edu.co/derecho/constitucion/antecedentes.html

20 IBÁÑEZ, ob. cit., 14, pp. 5-21.

21 Carlos Mario Molina y Pilar Cerón. Primeras reflexiones acerca del contenido normativo de la Ley 489 de 1998, 2004, [Consulta 1/5/2016], disponible en: http://www.scielo.org.co/scielo. php?script=sci_arttext\& pid=S0124-05792004000200005 
(i) Con la Ley 489 de $1998^{[22]}$ se ajustó la estructura administrativa del Estado al nuevo esquema constitucional que pretendía racionalizar el aparato estatal, lograr una mejor calidad y eficiencia de la función administrativa y, como consecuencia de esto, la satisfacción de las necesidades generales de todos los habitantes; de conformidad con los principios, finalidades y cometidos constitucionale ${ }^{23}$. Esta reforma mantiene vigentes las categorías de órganos que se habían concebido con anterioridad en las reformas de 1968 y 1976, y en su artículo 38 establece cómo se integra la rama ejecutiva del poder públi$\mathrm{CO}^{24}$. Además, en su literal g) dispuso que la rama ejecutiva del poder público

22 "Por la cual se dictan normas sobre la organización y funcionamiento de las entidades del orden nacional, se expiden las disposiciones, principios y reglas generales para el ejercicio de las atribuciones previstas en los numerales 15 y 16 del artículo 189 de la Constitución Política y se dictan otras disposiciones". Con esta ley se derogaron los decretos ley 1050 y 3130, expedidos en la reforma de 1968, y el Decreto Ley 130 de 1976.

23 Estas finalidades están contemplas en el artículo 2. ${ }^{\circ}$ de la Constitución Política, así: "Artículo 2. Son fines esenciales del Estado: servir a la comunidad, promover la prosperidad general y garantizar la efectividad de los principios, derechos y deberes consagrados en la Constitución, facilitar la participación de todos en las decisiones que los afectan y en la vida económica, política, administrativa y cultural de la Nación; defender la independencia nacional, mantener la integridad territorial y asegurar la convivencia pacífica y la vigencia de un orden justo. Las autoridades de la República están instituidas para proteger a todas las personas residentes en Colombia, en su vida, honra, bienes, creencias, y demás derechos y libertades, y para asegurar el cumplimiento de los deberes sociales del Estado y de los particulares".

$24 \mathrm{Al}$ determinar en su artículo 38 la estructura de la rama ejecutiva en el nivel nacional, estableció dos sectores, el sector central y el sector descentralizado, así: "Artículo 38.- Integración de la Rama Ejecutiva del Poder Público en el orden nacional. La Rama Ejecutiva del Poder Público en el orden nacional, está integrada por los siguientes organismos y entidades:

1. Del Sector Central:

a. La Presidencia de la República;

b. La Vicepresidencia de la República,

c. Los Consejos Superiores de la administración,

d. Los ministerios y departamentos administrativos;

e. Las superintendencias y unidades administrativas especiales sin personería jurídica.

2. Del Sector descentralizado por servicios:

a. Los establecimientos públicos;

b. Las empresas industriales y comerciales del Estado;

c. Las superintendencias y las unidades administrativas especiales con personería jurídica,

d. Las empresas sociales del Estado y las empresas oficiales de servicios públicos domiciliarios;

e. Los institutos científicos y tecnológicos;

f. Las sociedades públicas y las sociedades de economía mixta

g. Las demás entidades administrativas nacionales con personería jurídica que cree, organice o autorice la ley para que formen parte de la Rama Ejecutiva del Poder Público.

Parágrafo $1^{\circ}$.- Las sociedades públicas y las sociedades de economía mixta en las que el Estado posea el noventa por ciento (90\%) o más de su capital social, se someten al régimen previsto para las empresas industriales y comerciales del Estado. 
en el orden nacional estaría integrada por las demás entidades administrativas nacionales con personería jurídica que cree, organice o autorice la ley, aparte normativo que se revisará más adelante con el fin de determinar si las agencias estatales de naturaleza especial corresponden a las entidades consagradas en este literal.

(ii) La reforma administrativa denominada "Programa de Renovación de la Administración Pública" (PRAP) del Gobierno 2002-2006 ${ }^{[25]}$, encaminada a una modernización y racionalización de las funciones del Estado y a un Estado fiscalmente responsable. En desarrollo de esta reforma, entre otros, se expidió el Decreto 1760 de 2003, por el cual se escindió Ecopetrol y se creó la Agencia Nacional de Hidrocarburos (ANH) como una unidad administrativa especial con personería jurídica. Nótese que esta reforma ya utiliza la denominación de agencia, aunque mantiene la naturaleza de unidad administrativa especial para la ANH.

(iii) La reforma administrativa del Gobierno 2010-2014, la cual se inspiró, conforme quedó consignado tanto en el documento "Bases del Plan Nacional de Desarrollo 2010-2014"26 como en la Ley 1450 de $2011^{[27]}$, en los principios del "buen gobierno"28 como conductores institucionales para alcanzar

Parágrafo $2^{\circ}$.- Además de lo previsto en el literal c) del numeral 1 del presente artículo, como organismos consultivos o coordinadores, para toda la administración o parte de ella, funcionarán con carácter permanente o temporal y con representación de varias entidades estatales y, si fuere el caso, del sector privado, los que la ley determine. En el acto de constitución se indicará al Ministerio o Departamento Administrativo al cual quedaren adscritos tales organismos". Corte Constitucional, Sentencia C-702 de 1999.

25 Esta reforma, "de conformidad con lo señalado en la Directiva Presidencial número 10 de 2002 y en el Plan Nacional de Desarrollo 2002-2006, estaban orientadas a realizar una profunda renovación de la administración pública, modernizar y racionalizar el ejercicio de las funciones del Estado, acercar las entidades públicas al ciudadano y establecer un Estado fiscalmente responsable". Para ello se tramitó ante el Congreso una iniciativa para revestir al Presidente de la República de facultades extraordinarias, para, entre otras: "a) Suprimir y fusionar departamentos administrativos, determinar su denominación, número y orden de precedencia $;[\ldots]$ d) Escindir entidades u organismos del orden nacional creados o autorizados por la ley $;[\ldots]$ e) Crear las entidades u organismos que se requieran para desarrollar los objetivos que cumplían las entidades u organismos que se supriman, escindan, fusionen o transformen, cuando a ello haya lugar".

26 Departamento Nacional de Planeación, Bases del Plan Nacional de Desarrollo, Capítulo VII, Soportes transversales de la prosperidad democrática, pp. 470 y 473, [Consulta 26/02/2016], disponible en: https://colaboracion.dnp.gov.co/CDT/PND/8C.\%20Cap\%C3\%ADtulo\%20 VII.pdf

27 "Por la cual se expide el Plan Nacional de Desarrollo, 2010-2014".

28 Los postulados del buen gobierno tienen su génesis constitucional, en Colombia, en el artículo 209 de la Constitución que señala que la función administrativa está al servicio de los intereses generales y se desarrolla con fundamento en los principios de igualdad, moralidad, eficacia, economía, celeridad, imparcialidad y publicidad, mediante la descentralización, la delegación y la desconcentración de funciones. Tales postulados están establecidos igualmente en el artículo 3 de la Ley 489 de 1998 y en el artículo 3 del Có- 
la prosperidad nacional. En el capítulo VII de las Bases del Plan Nacional de Desarrollo, "Soportes transversales de la prosperidad democrática"29, se indica precisamente que "el fortalecimiento institucional a través del buen gobierno es un mecanismo quizás menos tangible y más complejo que los programas sociales o económicos, pero posiblemente más efectivo para alcanzar la prosperidad democrática", concluyendo que el éxito en la función está en la misma retroalimentación institucional. En el mismo capítulo del documento oficial se señala, citando a Adam Przeworski, que "el objetivo del Buen Gobierno es implementar un diseño institucional que maximice la probabilidad de que en la ejecución de su rol, las organizaciones públicas logren efectos de acuerdo a su misión: asignaciones eficientes, mitigación de las fallas de mercado y generación de equidad. Para ello, el diseño de las instituciones debe inducir y generar mecanismos transparentes que orienten las relaciones entre los ciudadanos, el sector privado y el sector público".

Ahora bien, la noción de buen gobierno encierra una dificultad de orden práctico: ella contiene diferentes acepciones según el enfoque desde el cual se estudie, por lo que presenta significados no siempre coincidentes. Por ejemplo, encontramos una definición de "buen gobierno" como: "aquel que promueve y logra que las organizaciones de la sociedad, públicas y privadas, brinden a los ciudadanos, especialmente a aquellos menos favorecidos, las oportunidades de mejorar sus capacidades y a través de ellas su calidad de vida. El "buen gobierno" es un facilitador, un canalizador de las aspiraciones ciudadanas, un constructor de vías efectivas y un administrador eficiente de los recursos públicos ${ }^{\prime \prime 30}$. Así mismo, el profesor Gerry Stoker, de la Universidad de Southampton, expone que en términos generales una política de buen gobierno puede resumirse en cinco paradigmas:

1. El 'buen gobierno' se refiere a un conjunto de instituciones y agentes procedentes del gobierno, pero también de fuera de él. 2. El 'buen gobierno' reconoce la pérdida de nitidez de los límites y las responsabilidades tocante a hacer frente a los problemas sociales y económicos. 3. El 'buen gobierno' identifica la dependencia de poder que existe en las relaciones entre las instituciones que intervienen en la acción colectiva. 4. El 'buen gobierno' se aplica a redes autónomas de agentes que

digo de Procedimiento Administrativo y de lo Contencioso Administrativo (Ley 1437 de 2011), que establece los principios orientadores de las actuaciones administrativas. Estos principios se han difundido ampliamente desde inicios de los años noventa a raíz de un estudio realizado por el Banco Mundial, sobre la crisis y el crecimiento sostenido en el África Subsahariana y la importancia del mencionado buen gobierno en el desarrollo económico.

29 Departamento Nacional de Planeación, Bases del Plan Nacional de Desarrollo, cit., 22.

30 Diego Younes Moreno, ob. cit., 13, p. 583; Id., El nuevo Estatuto de Organización y Funcionamiento de la Administración Pública: análisis y comentarios de la ley 489 de 1998, Bogotá: Ediciones Jurídicas Gustavo Ibáñez, 1999. 
se rigen a sí mismas. 5. El 'buen gobierno' reconoce la capacidad de conseguir que las cosas se hagan, que no se basa en el poder del gobierno para mandar o emplear la autoridad. Considera que el gobierno puede emplear técnicas e instrumentos nuevos para dirigir y guiar ${ }^{31}$.

Por su parte, el Banco Mundial, la Agencia Bilateral del Gobierno Británico y el PNUD, a los que alude Jokin Alberdi ${ }^{32}$, consideran que el buen gobierno es el que trasciende a lo eminentemente político y económico y se enfoca en asuntos relacionados con el bienestar social, teniendo en cuenta elementos como los factores culturales, las particularidades nacionales, los liderazgos y la responsabilidad política, los procesos de participación social, así como la construcción de capacidades. Es en este sentido que lo interpreta el PNUD al afirmar que el buen gobierno es "el ejercicio de la autoridad económica, política y administrativa para manejar los asuntos de un país en todos los niveles a fin de que el Estado promueva la cohesión social, la integración y el bienestar de su población". De ahí que para los efectos del presente trabajo se entienda por buen gobierno, en un sentido amplio, toda actuación que, en aplicación de principios como los consagrados en el artículo 209 de la Constitución Política, no sólo se ocupa de las problemáticas políticas, administrativas, económicas y sociales, sino que incluye además toda la complejidad que ello encierra y las diferentes interrelaciones prácticas entre las mismas, en procura del bienestar integral de la población y la realización de fines y cometidos estatales ${ }^{33}$.

Con base en los estándares de buen gobierno en los que parece inspirarse la reforma que nos ocupa, se intentó también generar mecanismos participativos en procura de procesos abiertos que fomenten la deliberación y la participación ciudadana de los actores públicos y privados en la ejecución, seguimiento y evaluación de la gestión pública, así como la creación y fortalecimiento de algunas entidades especializadas para que se articularan con la institucionalidad vigente, y la realización de ciertos ajustes normativos ${ }^{34}$. Así las cosas, entre los años 2011 y 2013 el Gobierno Nacional ${ }^{35}$ y el Congreso de la República

31 Gerry StOKER, "Buen gobierno como teoría: cinco propuestas", Revista Internacional de Ciencias Sociales, pp. 155.3-35, citado por Liliana Gómez, El buen gobierno: paradigmas y perspectivas políticas, [Consulta 26/02/2016], disponible en: http://ridum.umanizales.edu.co:8080/xmlui/ bitstream/ handle/6789/1860/Art\% C3\%ADculoBUENGOBIERNO\%20revisado.pdf?sequence=1

32 Jokin Alberdi. Diccionario de la Acción Humanitaria y Cooperación al Desarrollo, [Consulta 23/08/2015], disponible en: http://www.dicc.hegoa.ehu.es/listar/mostrar/24, Acepciones de Buen Gobierno, Anexo n. ${ }^{\circ} 1$

33 Lombard señala que dentro de la función del Estado regulador en la práctica necesariamente los problemas económicos y sociales se interrelacionan: MARTINE LOMBARD, "Régulateurs indépendants, mode d'emploi", en Régulation économique et démocratie, Paris: Dalloz, 2006, p. 4. Comisión de Infraestructura, Informe, Bogotá, 2012.

35 Mediante el artículo 18 de la Ley 1444 del 4 de mayo de 2011 se otorgaron facultades extraordinarias por 6 meses al ejecutivo para adelantar una reforma a la administración pública. 
emprendieron una reforma administrativa para crear, transformar y fortalecer algunas entidades especializadas con el fin de articularlas con la organización administrativa existente. Esta reforma creó diecisiete organismos, escindió y creó tres más y modificó la naturaleza jurídica de otros tres ${ }^{36}$, instituyendo un nuevo panorama de organización administrativa. Se observa un cambio de motivación, al menos en la intención expresada a nivel gubernamental, debido a que se pretende consolidar un Estado moderno democrático, social y participativo, que cuente con instituciones que generen mecanismos transparentes para orientar las relaciones entre los ciudadanos, el sector privado y el sector público, como condiciones para una eficaz y eficiente gestión institucional ${ }^{37}$.

Es en este contexto que surgen las agencias estatales, y dentro de estas las denominadas de "naturaleza especial", término con el que se quiso designar a un conjunto de unidades de servicios de la administración ${ }^{38}$, que, en razón de un procurado carácter técnico para cumplir sus funciones en el sector al que pertenecen, conocimiento especializado, perfil profesional y visión de la gerencia pública moderna, debían ser diferenciadas de otras formas clásicas de organización pública, determinadas por la Ley 489 de $1998^{[39]}$. Ahora bien, esta justificación de la aparición de agencias en nuestro ordenamiento jurídico, a partir de las exigencias de la nueva gerencia pública, no es aceptada por todos.

Una primera dificultad, para una aceptación de esta tesis, radica en el hecho de que tradicionalmente la noción de "agencia" tiene su origen en los derechos de la familia de la Common Law ${ }^{40}$, tradición jurídica que se aparta de la romano germánica desde la cual se ha dado la determinación de las entidades y organismos administrativos nacionales ${ }^{41}$. Esto dificulta todo ejercicio intelectual tendiente a determinar el contenido de la noción.

Ver Anexo 2: Entidades denominadas Agencias que tienen naturaleza de Unidad Administrativa Especial y Agencias Estatales de Naturaleza Especial.

37 Las facultades extraordinarias conferidas al Presidente de la República "para renovar y modificar la estructura de la Administración Pública Nacional serán ejercidas con el propósito de garantizar la eficiencia en la prestación del servicio público, hacer coherente la organización y funcionamiento de la Administración Pública y con el objeto de lograr la mayor rentabilidad social en el uso de los recursos públicos": parágrafo 1 del artículo 18 de la Ley 1444 de 2011.

38 Las unidades laborales se clasifican en: "simples (las constituidas sólo por puestos de trabajo o cargos) o complejas (las integradas por otras unidades menores). Toda unidad ha de estar integrada en un órgano, lo que no significa que todo órgano debe contar en su interior con unidades". Así, el órgano es una unidad organizativa cualificada que puede contar en su interior con una o varias unidades simples o complejas, algunas de las cuales pueden tener igualmente la condición de órganos. LUCIANO PAREJO, Lecciones de derecho administrativo, Bogotá: Universidad Externado de Colombia, 2011.

39 Artículo 38 de la Ley 489 de 1998; v. supra nota 20.

40 Sobre los orígenes de la Common Law y su diferencia con los derechos de la familia de tradición romano-germánica, vid. René DAVID. Le droit anglais, Paris: PUF, 10. a ed., 2003.

41 Jorge Iván Rincón. "Presentación", Revista Digital de Derecho Administrativo n. ${ }^{\circ}$ 13, enero- 
A pesar de su uso generalizado en nuestro sistema, no son aún unánimes las explicaciones dadas a la importación del término. Estas incluyen aquellas posturas que, como la de los autores de la reforma, sin ahondar en la ubicación de las agencias de naturaleza especial dentro de la estructura de la administración pública colombiana, resaltan que su importancia radica en el hecho de que ejecuten con criterios técnicos las políticas fijadas por el ministerio o departamento al que estén vinculadas, "de manera técnica, eficiente y ejecutiva, y ahí las agencias entran a desempeñar un papel protagónico. Este nuevo tipo de entidades deben trabajar por retos y no por problemas ${ }^{\prime 42}$. Un segundo enfoque pretende, a partir de una confrontación entre la noción de agencia y los criterios clásicos de organización administrativa del orden nacional, admitir su inclusión en nuestro sistema en razón de "la imposible tendencia al abandono de casillas en la organización administrativa, para abrirnos paso al reconocimiento de entidades administrativas en general y sin perjuicios organizacionales, en las que se pueda modelar en cada caso, y con mayor facilidad, respuestas a las necesidades materiales"43, o para "la creación de un nuevo modelo organizacional, no por la puesta en evidencia de una actividad precisa que deba tener un referente en este sentido, sino por la necesidad de encontrar un referente menos rígido en el cual se puedan concebir distintas funciones a ejercer, y mayores posibilidades de dotación de márgenes amplios y distintos de autonomía" 44 .

Otros consideran que la inclusión de agencias en nuestro sistema es una simple decisión política, que sigue una tendencia que existe en países miembros de la Organización para la Cooperación y el Desarrollo Económico (OCDE $)^{45}$ y que sería contraria a nuestra tradición jurídica ${ }^{46}$. Dentro de este marco, las

junio, Universidad Externado de Colombia, 2015, pp. 9-13, disponible en: http://revistas. uexternado.edu.co/index.php/Deradm/article/view/4183/4806

42 Elizabeth Rodríguez. "Reformas de la administración pública 2011 en Colombia: por un Estado más eficiente", Revista del CLAD sobre la Reforma del Estado y de la Administración (en línea) pp. 1-10, [Consulta 25/02/2016], disponible en: http://www.dgsc.go.cr/dgsc/documentos/ cladxvii/rodriel.pdf

43 Alberto Montaña. "La incorporación de agencias en la estructura administrativa colombiana del orden nacional. Una confrontación axiológica de dos modelos organizacionales de la administración pública", Revista digital de Derecho Administrativo n. ${ }^{\circ} 13$, enero-junio, Universidad Externado de Colombia, 2015, pp. 41-42, [Consulta 25/02/2016], disponible en: http://revistas.uexternado.edu.co/index.php/ Deradm/article/view/4185/4808

44 Ibíd., pp. 41-42.

45 AlejANDRA Boto. "La agencia como forma organizativa de optimización de servicios públicos. Pasado, presente y futuro en una España en crisis", Revista digital de Derecho Administrativo n. ${ }^{\circ} 13$, enero-junio, Universidad Externado de Colombia, 2015 pp. 45-61, disponible en: http://revistas.uexternado.edu.co/index.php/Deradm/article/view/4186/4809

46 Pese a esta contrariedad se pretende explicar su existencia. AlberTo MONTAÑa, ob. cit., 39 y Consuelo SarRia, "¿Las agencias son unidades administrativas especiales?", Revista digital de Derecho Administrativo n. ${ }^{\circ}$ 13, enero-junio, Universidad Externado de Colombia, 2015, 
agencias de naturaleza especial en la estructura de la administración pública colombiana parecen obedecer a las necesidades del mundo actual, permeado por fenómenos como la globalización ${ }^{47}$. En este sentido, se ha sostenido que las agencias "en el derecho colombiano no responden a unas características genéricas que las identifiquen y diferencien, ni tienen establecidas unas normas generales en relación con su naturaleza, su estructura, el régimen jurídico aplicable y su funcionamiento" 48 , siendo figuras extrañas "en un Estado en el que se sigue el modelo romano germánico y no el anglosajón"49, que ciertamente llegan a ser "más que unidades administrativas especiales [... y vienen a ubicarse en las categorías vigentes como entidades descentralizadas cuando tienen personalidad jurídica, con algunos aspectos especiales, previstos en cada caso concreto en sus propias normas de creación"

La ausencia de correspondencia de las agencias con las formas organizativas tradicionales no ha sido obstáculo para que un tercer sector de la doctrina considere que se está en presencia de una nueva forma d e organización, propia de las administraciones instrumentales, con vocación técnica, que sería la única en el futuro ${ }^{51}$. La tesis anterior es radicalizada de hecho por un sector de la doctrina española que incluso llega a considerar que

... las Agencias estatales no van a ser, sin más, un nuevo tipo de organismo público, sino la fórmula organizativa hacia la que, progresivamente, se van a reconducir aquellos organismos públicos existentes en la actualidad, cuya actividad y funcionamiento se ajusten al concepto de Agencia estatal y se estime oportuno y más eficaz su transformación en este tipo de organismo público. Así mismo, tras la entrada en vigor de esta Ley, la Agencia estatal será el tipo de organismo público que, con carácter general, se cree por la Administración General del Estado para dar respuesta a sus

pp. 237-252, disponible en: http://revistas.uexternado.edu.co/index.php/Deradm/article/ view/4193/4816

47 Al respecto algunos autores consideran "la globalización como un proceso complejo de intensificación, interrelación e interdependencia de las relaciones entre países, personas, economías, bienes, servicios, etc., cuyo motor o eje es la economía y los avances tecnológicos y comunicacionales. Este proceso da lugar a que la interrelación se efectúe de una manera más intensa e instantánea diluyendo las fronteras espaciales y temporales en un ámbito global": Gonzalo Andrés Ramírez Cleves, Pobreza, globalización y derecho: ámbitos global, internacional y regional de regulación, Bogotá: Universidad Externado de Colombia, 2009. Montaña, ob. cit., 39 y SARria, ob. cit., 42.

Montaña, ob. cit., 39 y SARria, ob. cit., 42.

Montaña, ob. cit., 39 y SARria, ob. cit., 42

Boto sostiene: "La nueva ley no deroga el sistema tradicional, en puridad solo añade un nuevo tipo de organismo público al sistema bipartito existente hasta el momento; no obstante, prevé que los organismos existentes se acaben transformando en agencias y que, a partir de su entrada en vigor, las agencias sean la forma habitual de creación de nuevas organizaciones instrumentales en la Administración General del Estado": ob. cit., p. 41. 
necesidades de descentralización funcional, si bien, excepcionalmente, subsistirán los restantes tipos de organismos públicos ${ }^{52}$.

De ahí que sea necesario ahondar en el debate en torno a la aparición de este tipo de estructuras en el derecho colombiano, a partir de un examen de su arquitectura interna y funciones.

Son justamente estas entidades, denominadas por los órganos legislativo y ejecutivo como agencias estatales de "naturaleza especial" ${ }^{53}$, las que por su aparición ${ }^{54}$ en la estructura de la administración pública colombiana constituyen el objeto de estudio del trabajo de investigación a desarrollar. De hecho, a partir de su incorporación en nuestro panorama organizacional se plantea el interrogante de saber si estos órganos responden a una naturaleza jurídica distinta a la de organismos y entidades que integran la estructura tradicional de la administración pública colombiana.

El problema jurídico aquí identificado adquiere especial connotación, en la medida en que ni en las normas de creación o transformación de las agencias de las que se ocupó la reforma originada en 2011, como tampoco en los estudios técnicos que le sirvieron de soporte, existe claridad jurídica sobre el significado de la noción de agencia estatal de naturaleza especial, ni se establece un referente conceptual claro sobre ella. Al igual que ocurrió cuando se crearon los establecimientos públicos y las unidades administrativas especiales, para justificar su creación o transformación se recurre al argumento de que se requiere contar con instituciones técnicas y especializadas que desarrollen funciones administrativas ligadas a finalidades de interés general.

Tratar de identificar la naturaleza de las agencias estatales de naturaleza especial requirió abordar nuestro estudio a partir de dos enfoques metodológicos convergentes: (i) un análisis de las instituciones denominadas "agencias"

Luis Manuel Cosculluela Montaner. "Las Agencias Estatales", Revista Española de Control Externo, n. ${ }^{\circ} 24$, pp. 29-53

53 Son agencias de naturaleza especial: la Agencia Nacional de Minería (Decreto 4134 de 2011) y la Autoridad Nacional de Televisión (Ley 1507 de 2012). La Agencia Nacional de Hidrocarburos (Decreto 4137 de 2011) y la Agencia Nacional de Infraestructura (Decreto 4165 de 2011) fueron transformadas en su naturaleza jurídica, de unidad administrativa especial y establecimiento público, respectivamente, a agencias estatales de naturaleza especial.

54 Ronald Pacheco sostiene: "A pesar de que en el artículo 211 de la Constitución y en el artículo 13 de la Ley 489 de 1998 se hace referencia a las 'agencias del Estado', la presencia de entidades con esta naturaleza sólo se ha venido a desarrollar ampliamente por el legislador a partir del año 2011. Ahora, si se revisan los decretos 1050 y 3130 de 1968 y 130 de 1976, en ninguna de estas normas aparece una entidad con denominación de 'agencia'": "La Autoridad Nacional de Televisión, ¿una agencia estatal independiente?", Revista digital de Derecho Administrativo n. ${ }^{\circ}$ 13, enero-junio, Universidad Externado de Colombia, pp. 63-98, disponible en: http://revistas.uexternado.edu.co/index.php/Deradm/article/ view/4187/4810 
en el derecho federal estadounidense, en donde esta noción tiene su origen, y (ii) una comparación al interior de nuestro sistema jurídico entre categorías tradicionales como la de unidad administrativa especial, a la que aluden en su naturaleza y funciones las agencias, y la de establecimiento público, a cuyo régimen jurídico y división de sus órganos principales de dirección entre colegiado y monocefálico reenvían ${ }^{55}$. Se buscó de este modo determinar si las agencias de naturaleza especial en Colombia encuadran con aquellas instituciones presentes en otros sistemas y que se denominan de igual manera, o si corresponden a un tipo tradicional de organismo de los que ha integrado nuestra administración pública del orden nacional, tal como esta es definida por el artículo 39 de la Ley 489 de 1998.

Del mismo modo, la comparación abarcó aspectos organizacionales y funcionales, buscando aclarar con ello si las agencias de naturaleza especial son autoridades independientes del ejecutivo ${ }^{56}$. Por ende, conformó también el marco de análisis la noción de autoridad administrativa independiente en Colombia, donde se ubican entidades de creación constitucional como son el Banco de la República y la Comisión Nacional del Servicio Civi1 ${ }^{57}$. Debe

55 Se trata de un doble ejercicio de comparación tendiente en un primer momento a comprender mejor la presencia de instituciones originadas o "importadas" desde otros sistemas, con el fin de luego verificar, en un segundo tiempo, su correspondencia con otras ya presentes en nuestro derecho de la organización. Sobre la utilidad de la comparación como ejercicio académico, vid. Pierre LeGrand, Le droit comparé, Paris: PUF, 1999.

56 Dentro del estudio técnico que soportó los actos de creación de algunas agencias se señala que se busca crear organismos independientes técnicamente. Por ende, es necesario revisar si estas agencias presentan atributos de independencia. Agencia Nacional de $\mathrm{Hi}$ drocarburos, "Consolidación institucional del sector de hidrocarburos. Transformación de la Agencia Nacional de Hidrocarburos. Estudio Técnico". Bogotá, 2011. Cámara de Representantes, Gaceta del Congreso n. ${ }^{\circ}$ 929, 2 de diciembre de 2011, "Ponencia", [Consulta 27/02/2016], disponible en: ftp://backups.senado.gov.co/atencion_ciudadana/Backup Mónica Vanegas/ATENCIÓN CIUDADANA/LEYES CON ANTECEDENTES/LEY 1 i Instituto Colombiano de Geología y Minería, Universidad Nacional de Colombia, "Estudio Técnico para la reestructuración de Ingeominas", 2012; Instituto Nacional de Concesiones, Unión Temporal Stratco Consultores Asociados - Nexus Banca de Inversión, "Estudio Técnico y propuesta para la reestructuración del Instituto Nacional de Concesiones en la Agencia Nacional de Infraestructura" Bogotá: 2011. Se entiende por independencia el conjunto de garantías orgánicas tendientes a aislar a las autoridades que son parte de la administración pública de las injerencias del ejecutivo, dentro de las cuales se incluyen diferentes dimensiones de autonomía, pero sin que estas sean suficientes, y que tienen como objeto blindarlas frente a las injerencias del ejecutivo: véase ANíBAL ZáraTE, L'indépendence des autorités de concurrence, Analyse comparative Colombie, France, États-Unis, thèse de doctorat, Université Paris II, Panthéon-Assas, dir. Martine Lombard, 2011, p. 45.

57 Corte Constitucional, Sentencia C-827 de 2001, donde se sostiene: "La especial autonomía que la Constitución predica del Banco de la República y de su Junta Directiva como autoridad monetaria, crediticia y cambiaria proyecta en nuestra organización constitucional la presencia de las denominadas autoridades independientes que en la doctrina y en la organización de los Estados ha venido enfatizándose bajo la primigenia inspiración 
asimismo hacerse una precisión sobre el objeto de la investigación: si bien el objeto de estudio fueron las agencias nacionales de naturaleza especial, se hicieron referencias puntuales sobre aspectos organizacionales y de funcionamiento de las agencias estatales, cuyas normas de creación o transformación les asignaron como naturaleza jurídica la de unidades administrativas especiales, a pesar de la denominación dada en la reforma de $2011^{[58]}$.

\section{PRIMERA PARTE: LA PERÍFRASIS EN MATERIA DE ORGANIZACIÓN ADMINISTRATIVA}

La organización administrativa es un concepto complejo, difícil de determinar, que reúne elementos técnicos ${ }^{59}$ y políticos ${ }^{60}$. La administración pública, en este sentido, puede ser concebida como sujeto y como organización. Jorge Iván Rincón ha señalado al respecto que "ver a la Administración como sujeto permite explicar cómo en el Estado se distribuyen las competencias o, lo que es igual, la determinación de su capacidad de actuación. Por contera, se trata, en el caso del derecho administrativo, de hacer posible aplicar el principio

de instituciones similares de los Estados Unidos, posteriormente del Reino Unido y más recientemente del constitucionalismo europeo continental (Francia, España, por ejemplo), encargadas de la regulación de actividades sociales -organismos reguladores-con el agregado de las especiales peculiaridades que evidencia el modelo de banca central también paulatinamente acogido en diferentes Estados". Es preciso indicar cómo el juez constitucional colombiano utiliza los términos independencia, de un lado, y autonomía, de otro lado, para definir cualidades reconocidas a algunos organismos; atributos que se designan de manera inversa en las acepciones de otros países, como lo demuestran los ejemplos francés y estadounidense: véase Zárate, ob. cit., p. 41.

58 Entre estas se encuentran la Agencia Nacional de Defensa Jurídica del Estado y la Agencia Nacional de Contratación Pública-Colombia Compra Eficiente, v. Anexo 2.

59 En este sentido, la organización administrativa puede entenderse como la configuración de los medios para la realización de los fines, con arreglo a directrices predeterminadas. La estructura es esencial, pero también son necesarios los elementos financieros y jurídicos para que su acción se ajuste a cada circunstancia, para el logro de la eficacia funcional.

60 Desde el campo de la ciencia política, uno de los principales exponentes de las escuelas del pensamiento político sobre la burocracia, Max Weber, considera que esta "es el pilar fundamental del moderno Estado de derecho, en la medida que permite diferenciar la esfera político-administrativa de otras esferas o niveles (la religión, la economía...). En este sentido cumple un papel racionalizador. Incluso si se defiende que la violencia del Estado es 'legítima', es porque se diferencia claramente de la violencia feudal indiscriminada. Si existe un estado de derecho necesariamente debe existir una burocracia que dé sentido y estructura organizativa a la ley": Burocracia, Max Weber, [Consulta 11/05/2016], disponible en: http://mbapensamiento.blogspot.com.co/2011/08/burocracia-max-weber.html Según Weber, "el modelo burocrático es aquel tipo ideal donde se maximiza la eficiencia de la organización gracias a que existen reglas generales y abstractas, procedimientos estandarizados, división racional del trabajo, despersonalización y jerarquía": Burocracia estatal. Conceptos de Ciencia Política, Administración, Soberanía, [Consulta 11/05/2016], disponible en: http://historiaybiografias.com/ciencia_politica3/ 
según el cual cuando el incumplimiento de normas jurídicas genera un daño que el particular no está en la obligación legal de soportar, deben arbitrarse mecanismos a efectos de que la autoridad pública responda"61. A su turno, la administración pública como organización implica ubicarse en un momento anterior para establecer cómo y cuál debe ser la estructura más adecuada para alcanzar unos fines en función de la satisfacción de unas necesidades previamente identificadas ${ }^{62}$.

En Colombia la Ley 19 de 1958, en su artículo 1, estableció el objeto de la reorganización de la administración pública ${ }^{63}$, el cual se ha observado a lo largo de las distintas reformas ${ }^{64}$, caracterizadas por la creación, supresión y fusión de entidades públicas y que se basaron en conceptos que en la actualidad hacen parte de los principios y postulados del buen gobierno ${ }^{65}$. A pesar de todos los cambios en organismos y entidades, las categorías tradicionales de la administración pública del orden nacional ${ }^{66}$ heredadas del derecho francés se han mantenido, aun cuando con recientes reformas administrativas han aparecido estructuras que se han denominado agencias ${ }^{67}$, concepto que en la organización administrativa colombiana genera dificultades, considerando que este se aparta de la tradición desde la que se han concebido las entidades y organismos nacionales.

61 Jorge IvÁn Rincón CóRdoba. "Límites orgánicos de la responsabilidad del Estado", en XVI Jornadas Internacionales de Derecho Administrativo, Bogotá, 2015, p. 130.

62 Ibíd.

63 Que no es otro que asegurar la coordinación y la continuidad de la acción oficial, la simplificación en los trámites y procedimientos, evitar la duplicidad de funciones y propiciar el ejercicio del control administrativo; v. supra nota 1.

$64 \mathrm{Al}$ respecto se destaca que para efectos del presente trabajo se estudiaron las reformas administrativas llevadas a cabo a partir de 1968 en las cuales se hace referencia a los órganos tradicionales de la administración pública, que son los que se contrastarán con las agencias estatales de naturaleza especial hasta las reformas del gobierno actual.

65 Sobre este concepto, vid. supra notas 24,27 y 28

66 A título de ejemplo y por la importancia de su existencia frente al objeto del presente trabajo, se hace referencia a la adopción de estructuras, concebidas ante una realidad que demostró que el Estado, además de atender funciones administrativas y prestar servicios públicos, ejercía actividades económicas con ánimo de lucro semejantes a las que realizaban los particulares; fue en esta reforma administrativa de 1968 que se determinó que en el país existen establecimientos públicos encargados esencialmente de atender funciones administrativas y de prestar servicios públicos conforme a las reglas del derecho público, así como empresas industriales y comerciales del Estado que desarrollan actividades de naturaleza industrial y comercial y de gestión económica, sujetas a las reglas del derecho privado, salvo las excepciones que consagra la ley; criterio que fue acogido por la legislación vigente (Ley 489 de 1998).

67 En el año 2003 se utiliza por primera vez esta denominación cuando se crea la Agencia Nacional de Hidrocarburos, como unidad administrativa especial. En 2010-2014 se generaliza esta denominación en la administración pública colombiana del orden nacional. 
Así las cosas, es necesario identificar su sentido, con el fin de establecer si corresponde a un tipo tradicional de organismo de la administración ${ }^{68}, \mathrm{o}$ si este encaja en una noción más general, similar a la que se le ha dado en el derecho comparado. A partir de un análisis de la noción en el derecho federal de Estados Unidos, en donde tuvo su génesis, se observa precisamente cómo este término alude a una noción equivalente a la de "autoridad administrativa" (1). Esta generalidad de la noción de agencia contrasta a su vez con una evolución al interior de la administración nacional colombiana: la pérdida del carácter especial del término "unidad administrativa especial", el cual, puede afirmarse, aparece hoy en día de forma incluso más común que el de "establecimiento público" (2).

\section{La Generalidad Del término "Agencia"}

Con la reciente reforma 2010-2014 se creó y modificó ${ }^{69}$ la naturaleza jurídica de ciertas entidades y proliferaron en la estructura de la administración pública las "agencias nacionales" para referirse a organismos administrativos que, bajo un modelo de gestión orientado al logro de resultados y a la eficaz utilización de recursos públicos, se busca concebir, según algunos de los estudios técnicos que soportaron la reforma, como especializados y técnicamente independientes ${ }^{70}$. Dentro de estas aparecen las llamadas "agencias estatales de naturaleza especial", como unidades de servicios, a las que a la hora de ubicarlas en la estructura de la administración e identificar sus características, ante la ausencia de un norte conceptual en sus normas de creación ${ }^{71}$, generan ambigüedades.

68 "Por tradicional se quiere hacer referencia a denominaciones de organización administrativa existentes desde la composición normativa de 1968, o cuando menos desde la sanción del instrumento normativo vigente que se ocupa de ello: ley 489 de 1998": AlBerTo MONTAÑA, ob. cit., 39, p. 30.

69 Con la Ley 1444 de 2011 se otorgaron facultades extraordinarias al Presidente de la República para modificar la estructura de la administración pública. Con esta reforma también se buscó liquidar entidades que presentaban fallas estructurales en su diseño o en la concepción histórica de sus facultades, como fueron los casos del Departamento Administrativo de Seguridad (DAS) y de la Dirección Nacional de estupefacientes (DNE), por citar algunos ejemplos. Algunos autores consideran que "Estas liquidaciones han tenido el mérito de no estar motivadas por el afán fiscalista, ya que menores gastos de operación no necesariamente conducen a mejor desempeño estatal": ÉdGAR GOnZÁLEZ SALAS, "La reforma al Estado: bondades y limitaciones", razonpublica.com, febrero de 2012, (en línea) [Consulta 6/3/2016], disponible en: http://www.razonpublica.com/index.php/politica-ygobierno-temas-27/2707-lareforma-al-estado-bondades-y-limitaciones.html

70 Agencia Nacional de Hidrocarburos, "Consolidación institucional del sector de hidrocarburos. Transformación de la Agencia Nacional de Hidrocarburos. Estudio Técnico", Bogotá, 2011.

71 Alberto Montaña, ob. cit., 39, p. 29. 
Sobre las ambigüedades que se presentan en los procesos de reformas administrativas, González Salas, ha señalado: "Es de rescatar el esfuerzo gubernamental por avanzar en reformas transversales sostenibles, que potencien la gestión hacia un Estado eficaz. Algunas de estas reformas se han desenvuelto sin embargo en ambigüedades, aunque otras han alcanzado con claridad sus cometidos" ${ }^{\prime \prime 2}$.

Para determinar qué se entiende por agencia ${ }^{73}$ en nuestro ordenamiento, y si con su incorporación se creó en la administración pública nacional una estructura administrativa diferente de las tradicionales, es importante, en primer lugar, realizar un análisis comparativo de las instituciones denominadas "agencias" en el derecho federal estadounidense, con el fin de demostrar que en dicho sistema la agencia es una noción que no alude a una categoría de órgano de la administración (1.1), sino que alude a cualquier "autoridad administrativa" (1.2). Así mismo, es pertinente referirse a aquellos acontecimientos ${ }^{74}$ que promovieron su surgimiento en la estructura administrativa federal de Estados Unidos, dentro de los cuales apareció la necesidad de regular ciertas actividades económicas, como el transporte férreo de mercancías ${ }^{75}$. En este

72 Édgar González Salas. "La reforma de la administración pública 2002-2009", Revista Política Colombiana, octubre-diciembre, 2009, (en línea), pp. 29-32, [Consulta 6/3/2016], disponible en: http://politica colombiana.net/pdfs/2edicion/articulo02.pdf

73 "Agencia" es una palabra que procede del latín agentia y tiene su origen en agens, que significa "cualidad del que hace". Sus componentes léxicos son: agere (mover, hacer actuar, llevar adelante actuar), 'nt' (el que hace la acción), más el sufijo 'ia' (cualidad). Para el diccionario de la Real Academia de la Lengua Española el término "agencia" significa "Oficio o encargo de agente u organización administrativa especializada a la que se confía la gestión de un servicio". Véase Aleyda Palacios Amaya, "Trascendencia del concepto de agencia estatal en la estructura del poder público colombiano", trabajo de grado, Universidad Militar Nueva Granada, Bogotá, 2015.

74 "En 1887, el número 2 de la Political Science Quarterly publicó un ensayo de Woodrow Wilson (por entonces, joven profesor universitario) considerado como el primer estudio científico sobre la Administración pública en Estados Unidos. Casualmente -o no-, ese mismo año fue creada la Interstate Commerce Commission, la primera agencia reguladora independiente, concebida como una 'comisión' con potestades de carácter normativo (en cierto modo homologables a los poderes calificados en nuestro sistema como potestad reglamentaria) e, incluso, de naturaleza jurisdiccional. Esta agencia, junto con las que posteriormente se irían constituyendo, se configuraron como la esencia misma del Derecho Administrativo norteamericano, siendo identificadas como su célula madre. Este era el objeto y objetivo principal del Derecho Administrativo en Estados Unidos: el estudio de las agencias y determinar el modo en que se desenvolverían serenamente en el sistema de tres poderes bien definidos y delimitados que su Constitución había diseñado. Ciento veinte años después de la creación de la primera agencia norteamericana, sigue siendo un hito cuestionado": Jesús Avezuela CárCel, Agencias. El ejemplo norteamericano, noviembre, 2008, [Consulta 14/05/2016], disponible en: http://www.funciva.org/uploads/ficheros_ documentos/1225902539_agencias.pdf

75 Esto en razón del vacío que dejó la decisión Wabash, St Louis \& pac. Ry. v. Illinois, 118 US 557, 577 (1886), la cual estableció que solo el gobierno federal es competente para regular el 
sentido Avezuela sostiene: "La Administración de agencias en Estados Unidos es, esencialmente, fruto de una exigencia federal práctica, principalmente la interpelación de atender a una serie de necesidades - muchas de ellas, además, técnicamente complejas- a las que el Congreso no alcanzaba. Las agencias como poder administrativo, técnico, apolítico, diferente del poder ejecutivo atribuido por la Constitución al Presidente", surgen entonces por una determinación del Congreso federal ${ }^{76}$.

En este orden de ideas, seguidamente se revisará la noción que existe de agencia en el derecho estadounidense, que es el principal referente en esta investigación, y luego se analizará si el concepto en Colombia corresponde a esa noción, lo cual se abordará en los apartes subsiguientes.

\subsection{La agencia no es una categoría de organización de la administración}

En Estados Unidos, antes de la década de los treinta, se crearon las primeras agencias estatales, independientes o no, como la Interstate Commerce Commission (Comisión Interestatal de Comercio), el Army Corps of Engineers (Cuerpo de Ingenieros del Ejército), la Federal Railroads Administrations (Administración Federal de Ferrocarriles) y la Federal Trade Commission (Comisión Federal de Comercio) ${ }^{77}$. Sin embargo, la mayoría de las agencias en Estados Unidos surgen como respuesta a la crisis de 1929, bajo el gobierno de Franklin D. Roosevelt, quien estableció medidas de intervención para reactivar la economía, disponiendo así un nuevo orden para este país denominado el "New Deal"77, cuyo propósito

comercio entre los estados federados. Así, fue necesario crear un órgano regulador federal para esta actividad.

76 Jesús Avezuela, Agencias. El ejemplo norteamericano, cit.

77 La Interstate Commerce Commission (Comisión Interestatal de Comercio), primera agencia reguladora independiente, creada en 1887, concebida como una "comisión" con potestades de carácter normativo, encargada de regular la economía y los servicios de transporte ferroviarios (y más tarde otros sistemas de transporte, excepto el aéreo) para asegurar precios justos, eliminar la discriminación de precios, y para regular otros aspectos de las empresas de transporte público, como los conflictos laborales, incluyendo las líneas de autobuses interestatales y empresas telefónicas. La agencia fue abolida en 1995 y sus funciones fueron transferidas a la Comisión de Transporte Terrestre (Surface Transportation Board). El Army Corps of Engineers (Cuerpo de Ingenieros del Ejército), agencia federal, tenía por misión "proporcionar servicios de ingeniería pública vitales en la paz y en la guerra para reforzar la seguridad de la Nación, activar la economía y reducir los riesgos de desastres". La Federal Railroads Administrations (Administración Federal de Ferrocarriles) estaba encargada de la regulación de la seguridad del sistema ferroviario de la Nación y el desarrollo del tren interurbano de pasajeros, y la Federal Trade Commission (Comisión Federal de Comercio), agencia independiente creada en 1914, tenía la función principal de proteger los derechos de los consumidores y la eliminación y prevención de prácticas que atentaran contra la libre competencia.

78 "En efecto, Roosevelt asumió el poder en circunstancias dramáticas: bancos quebrados, 
consistió en una serie de disposiciones gubernamentales para enfrentar los efectos negativos de la Gran Depresión. En términos generales, esta política fue expansiva toda vez que buscaba poner en marcha mecanismos de control y vigilancia sobre el comportamiento del mercado; por ello las agencias son llamadas a ejercer, desde una posición a veces independiente del ejecutivo, la garantía de los derechos colectivos de los ciudadanos. Así las cosas, a partir de la década de 1930 se da una multiplicación de las agencias en el derecho federal estadounidense, donde desarrollan actividades de interés público, a través del ejercicio de funciones que les señalan sus actos de creación ${ }^{79}$.

De la revisión realizada al modelo estadounidense se observa que el concepto de agencia se ha considerado como referente genérico de autoridad o entidad pública, resultando tan amplio que, en la administración pública del orden federal que aquí se estudia, puede indicarse que la agencia encuentra una equivalencia con el término de autoridad administrativa, formando en algunos casos parte de la rama ejecutiva del poder público, mientras que en otros se encuentra fuera de ella. Por esta circunstancia la doctrina de Estados Unidos ha clasificado a las agencias en dos grandes tipos: las agencias independientes, que escapan del control directo del ejecutivo y en las que las decisiones de nombramiento y destitución de su personal directivo proceden con el consentimiento del Senado y cuando concurren causales de ley; y las agencias ejecutivas, que están sometidas a la voluntad del ejecutivo e integran esta rama del poder público ${ }^{80}$. Esta clasificación alude a las relaciones que las agencias federales mantienen con el Presidente, cabeza visible de la administración pública del orden federal, y no a las características o funciones comunes que

catorce millones de parados y los granjeros en revolución. Las alternativas eran la de anclarse en la clásica política económica del laissez faire con el fin de que las fuerzas del mercado corrigieran la situación y restablecieran el equilibrio, la de girar hacia el socialismo suprimiendo la propiedad privada y los medios de producción, o la de la economía dirigida o planificada, siendo esta última la que terminó triunfando": Jesús Avezuela Cár$\mathrm{CEL}$, Agencias. El ejemplo norteamericano, cit.

79 Ejemplo, Sección 4 A, Securities Exchange Act of 1934, delegación de funciones a la Comisión del Mercado de Valores (Securities and Exchange Commission). Además de su actual responsabilidad, la Comisión de Valores debe tener la capacidad de delegar, mediante disposiciones públicas o reglamentaciones, algunas de sus funciones a una división de la misma Comisión, a un determinado Comisionado, a un juez de la rama administrativa o a un empleado o miembro de la directiva ${ }_{i}$ incluso funciones tales como realizar audiencias, determinaciones, órdenes, certificaciones, reportes o de alguna manera poder actuar en cualquier situación relacionada con su propio trabajo, su negocio o algún asunto relacionado. En ningún caso en esta sección se considerará que se sustituyen las disposiciones de la sección 556(b) del numeral 5, o se autoriza la delegación de la función correspondiente a reglamentación tal y como se encuentra definida en el subcapítulo II del capítulo 5 numeral 5, de la Legislación de Estados Unidos, referente a normas generales diferentes a las que tienen alguna aplicabilidad específica o a la definición de cualquier norma en virtud de la sección 19(c) de este Capítulo (trad. libre).

80 Alberto Montaña, ob. cit., 39, pp. 33-34, Ronald Pacheco, ob. cit., 50, p. 71. 
cumplen, con mayor o menor autonomía, dependiendo de los controles de los que sus actividades y órganos de dirección pueden ser objeto ${ }^{81}$. Pero no significa que con esta clasificación se entienda crear categorías de organismos con un régimen jurídico y funciones diferentes como parece ocurrir, al menos en su origen, en el derecho francés y en el derecho colombiano ${ }^{82}$.

En este sentido, más que una categoría de organización de la administración pública, el concepto de agencia en Estados Unidos se refiere a una diversidad de organizaciones ${ }^{83}$ (comisiones, juntas, autoridades, oficinas, etc.) que desempeñan funciones de carácter gubernamental y que en algunos casos pueden ser externas al marco del gobierno ${ }^{1184}$. Al respecto Montaña sostiene que en Estados Unidos las agencias "no son ningún tipo, sino por el contrario un género en el que pueden gozar de mayor o menor autonomía, de mayores o menores controles, que pueden desarrollar variados tipos de actividades, y que para ello pueden tener distintos tipos de funciones (rulemaking, adjudication y quasijudicial functions) que no necesariamente confluyen" ${ }^{115}$.

El carácter general del concepto de agencia en el derecho estadouniden$\mathrm{se}^{86}$ lleva a plantearse una serie de interrogantes alrededor de su adecuación e instauración jurídica en el derecho público colombiano, razón por la cual debe indagarse si el legislador buscaba diferenciarlas sustancialmente de las categorías tradicionales de la administración, creando una nueva forma orgánica y jurídica denominada agencia de naturaleza especial, o si su intención no era otra que incorporar la denominación de agencia ${ }^{87}$, sin que esto signifique que su naturaleza jurídica sea diferente a la de unidad administrativa especial o de establecimiento público, categorías de órganos tradicionales de la administración pública nacional.

En efecto, si estas agencias de naturaleza especial no tienen suficientes elementos jurídicos y administrativos diferenciables, que demuestren que corresponden a una categoría distinta de organización a las que tradicionalmente

81 Alberto Montaña, ob. cit., 39, pp. 34-35

82 Alberto Montaña, ob. cit., 39, pp. 34-35.

83 Por ejemplo, la Interstate Commerce Commission (Comisión Interestatal de Comercio), concebida como una "comisión", o la Junta de Gobernadores de la Reserva Federal, que cumple funciones de banca central.

84 Sobre este aspecto, Giandomenico Majone sostiene que "agencia no es un término técnico, sino más bien una etiqueta que sirve para referirse a una diversidad de organizaciones". PARDO, ob. cit., 4, pp. 155-159.

85 Montaña, ob. cit., 39, p. 35

86 Ejemplos de la generalidad con que en el ordenamiento jurídico colombiano se utiliza el término "agencia" se encuentran en los artículos 211 de la Constitución Política y 13 de la Ley 489 de 1998, en los que se indica que la ley señalará las funciones que el Presidente de la República puede delegar, entre otras, en "agencias del Estado".

87 Podría señalarse que se acude a esta denominación de agencia considerando lo señalado en el artículo 211 de la Constitución y en el artículo 113 de la Ley 489 de 1998, en que se utiliza este término de forma genérica. 
han integrado la administración, se presentaría una remisión de este concepto a esas nociones orgánicas y funcionales de la administración pública, con lo cual podría señalarse, además, que, al margen de su denominación de agencia, esa expresión no alude en estricto sentido a una nueva categoría de organización de la administración pública nacional, sino a una autoridad administrativa en sentido genérico, como a continuación se estudia.

\subsection{La agencia como "autoridad administrativa"}

La Ley de Procedimiento Administrativo de Estados Unidos, que regula los procesos decisorios de todas las instancias del gobierno federal, señala que agencia es "toda autoridad del Gobierno de los Estados Unidos, que se encuentre o no sujeta al control de otra autoridad, a excepción del Congreso, las cortes federales, los gobiernos de los territorios o posesiones de Estados Unidos, el gobierno del Distrito de Columbia, las cortes marciales y las comisiones militares ${ }^{\prime \prime 8}$, noción de la cual se concluye con claridad meridiana que las agencias estadounidenses aluden a toda autoridad de carácter administrativo.

En Colombia, conforme lo previsto en el artículo 2. ${ }^{\circ}$ de la Ley 1437 de $2011^{[89]}$, autoridades administrativas son todos los organismos y entidades que cumplan funciones administrativas ${ }^{90}$, cualquiera que sea la rama del poder público a la que pertenezcan, o aun estando por fuera o siendo independiente de las mismas, es decir, como lo sostiene la Corte Constitucional: "En suma, se trata de la noción de autoridad administrativa en sentido funcional: todo titular de función administrativa, independiente de su ubicación orgánica, del nivel territorial de actuación o de su condición de particular" ${ }^{\prime \prime 1}$.

En este sentido, el derecho colombiano en el artículo 211 de la Constitución Política de 1991, así como en el artículo 113 de la Ley 489 de 1998, hace

88 Traducción libre de la Ley de Procedimiento Administrativo de Estados Unidos, Título 5, Sección 551. Además de las exclusiones señaladas en la definición de agencia, esta ley da una lista de otras exclusiones específicas, es decir, señala que otras autoridades no son agencia. PACHECO, ob. cit., 50, p. 70.

89 "Por la cual se expide el Código de Procedimiento Administrativo y de lo Contencioso Administrativo".

90 Como lo sostiene la doctrina, "Una función administrativa entendida entonces como un conjunto de actividades particulares, disímiles entre sí, pero diversas de aquellas generales de Estado y particulares propias de la función judicial y legislativa, que dan desarrollo directo a las finalidades del Estado, consagradas de manera positiva en la Constitución Política, que pueden ser desarrolladas por distintos sujetos de derecho, habilitados para ello, con el respeto y cumplimiento del ordenamiento jurídico superior": ALBERTO MONTAÑA, Fundamentos de derecho administrativo, Bogotá: Universidad Externado de Colombia, 2010, p. 124.

91 Corte Constitucional, Sentencia C-816, 2011, Disponible en: http://www.corteconstitucional.gov.co/relatoria/2011/C-816-11.htm 
referencia a las "agencias del Estado"92, de manera genérica, como autoridades administrativas, sin que exista un desarrollo normativo sobre qué debe entenderse o representa este término.

En este contexto y sólo a partir de la Constitución Política de 1991, se observa un empleo recurrente del término "agencias estatales", concepto que como se vio es propio de otros sistemas, como el estadounidense, pero que en las diversas reformas administrativas realizadas a partir de 1968 no había sido utilizado. En efecto, si se revisan estas reformas ${ }^{93}$, varios son los desarrollos que se presentaron en relación con las autoridades administrativas colombianas, y fueron múltiples las entidades administrativas que surgieron como respuesta organizacional a las necesidades estatales ${ }^{94}$. Estas entidades han sido tipificadas por la ley y como tal detentan unas características, como es el caso, entre otros, de los establecimientos públicos y las unidades administrativas especiales, que desarrollan las funciones que les señalan sus actos de creación. Sólo a partir del año 2003, con la creación de la Agencia Nacional de Hidrocarburos, como una unidad administrativa especial ${ }^{95}$, se utiliza la denominación de agencia para designar una estructura específica de la administración pública del orden nacional, término que se generaliza con la reforma administrativa llevada a

92 Artículo 211 de la Constitución Política: "La ley señalará las funciones que el Presidente de la República podrá delegar en los ministros, directores de departamentos administrativos, representantes legales de entidades descentralizadas, superintendentes, gobernadores, alcaldes y agencias del Estado que la misma ley determine. Igualmente, fijará las condiciones para que las autoridades administrativas puedan delegar en sus subalternos o en otras autoridades". "Artículo 13, Ley 489 de 1998: Delegación del ejercicio de funciones presidenciales. Modificado por el art. 45, Decreto Nacional 019 de 2012. Sin perjuicio de lo previsto en la Ley 142 de 1994 y en otras disposiciones especiales, el Presidente de la República podrá delegar en los ministros, directores de departamento administrativo, representantes legales de entidades descentralizadas, superintendentes, gobernadores, alcaldes y agencias del Estado el ejercicio de las funciones a que se refieren los numerales $13,20,21,22,23,24,26,27$ y 28 del artículo 189 de la Constitución Política".

93 Decretos 1050 y 3130 de 1968 y 130 de 1976, derogados por la Ley 489 de 1998.

94 Al respecto, debe indicarse que el derecho administrativo, desde "esta perspectiva, no solo estudia los órganos típicamente administrativos, sino también las funciones administrativas ejercidas por cualquier otro órgano o poder del Estado, o por los particulares como forma de participación en la gestión administrativa": Jaime Orlando SAntofimio Gamboa, Tratado de derecho administrativo, Bogotá: Universidad Externado de Colombia, t. I, 3. ${ }^{a}$ ed., 2013, p. 172 .

95 El artículo 2. ${ }^{\circ}$ del Decreto 1760 de 2003, por el cual se escindió Ecopetrol y se creó, entre otras, la Agencia Nacional de Hidrocarburos, expresamente señaló: "Créese la Unidad Administrativa Especial denominada Agencia Nacional de Hidrocarburos, ANH, entidad adscrita al Ministerio de Minas y Energía, con personería jurídica, patrimonio propio, autonomía administrativa y financiera, sometida al régimen jurídico contenido en el presente decreto y, en lo no previsto en él, al de los establecimientos públicos, de conformidad con lo dispuesto en la Ley 489 de 1998 y en las normas que la sustituyan, modifiquen o adicionen". 
cabo en 2010-2014. Sin embargo, expresamente se señala que se crea una unidad administrativa especial denominada Agencia Nacional de Hidrocarburos.

Así las cosas, es posible sostener que, al margen de su denominación, "agencia" no alude en estricto sentido a una nueva categoría de organización de la administración pública colombiana, sino que es un término que designa a cualquier autoridad administrativa. En efecto, ante la ausencia de una tipificación conceptual propia y la omisión en sus normas de creación y/o transformación de unas características que permitan identificarlas frente a otras autoridades, se puede señalar que en Colombia el término "agencia" aparece empleado como sinónimos de autoridad administrativa, mientras que las nociones de unidad administrativa especial y de establecimiento público hacen referencia a tipos de autoridades administrativas o agencias. Ahora bien, el legislador en el artículo 38, literal g, de la Ley 489 de 1998 contempló a los establecimientos públicos, unidades administrativas especiales y a las demás entidades creadas por ley o con su autorización ${ }^{96}$, como parte integrante de la rama ejecutiva ${ }^{97}$. ¿Podemos afirmar con certeza que las agencias estatales de naturaleza especial, cuyo objeto principal parece ser el ejercicio de funciones administrativas propias de un ministerio o departamento administrativo, encajan en esas otras entidades creadas por ley o con su autorización? ¿No es acaso la realización de actividades ministeriales o de los departamentos administrativos la finalidad de las unidades administrativas especiales? Más que identificar una categoría de órgano distinta, el término agencia parece denominar, de manera general, categorías de autoridades administrativas que ya han existido en nuestra organización.

Lo expuesto conduce a su vez a abordar la revisión de la pérdida del carácter "especial" de las unidades administrativas especiales y la generalidad del concepto de establecimiento público.

2. LA PÉRDIDA DEL CARÁCTER "ESPECIAL" DE LA UNIDAD ADMINISTRATIVA ESPECIAL; y DE LA "GENERALIDAD" DEL ESTABLECIMIENTO Público

En Colombia, como lo ha indicado Rodríguez ${ }^{98}$, dentro de la estructura de la administración pública, "aunque de manera un tanto confusa, también se ha querido conservar la clasificación entre organismos principales, organismos adscritos y organismos vinculados, que venía aplicándose desde el decreto-ley

96 Literal g del artículo 38 de la Ley 489 de 1998; vid. supra nota 20.

97 Se exceptúa la Autoridad Nacional de Televisión, que por expresa disposición del parágrafo 2. ${ }^{\circ}$ del artículo $2{ }^{\circ}$ de la Ley 1507 de 2012 se excluye de los controles de tutela y jerárquico. De ahí que pueda decirse que no se encuentra adscrita a un organismo principal de la rama ejecutiva.

98 Libardo RodríGuez. Estructura del poder público en Colombia, cit., p. 73. 
1050 de 1968", dentro de los cuales encontramos las unidades administrativas especiales y los establecimientos públicos.

Así las cosas, con la reforma de 1968 surgen las unidades administrativas especiales que fueron contempladas para la atención de programas propios de un ministerio o departamento administrativo, y que tendrían un régimen especial en razón de la naturaleza de sus funciones o del origen de sus recursos, el cual sería determinado por la ley que las crease, perteneciendo al nivel central, pues carecían de personería jurídica. Con la expedición de la Ley 489 de 1998 se reitera que las unidades administrativas especiales que no tengan personería jurídica ejecutarán programas propios de un ministerio o departamento administrativo y serán del nivel central ${ }^{99}$, y que las que tengan personería jurídica serán entidades descentralizadas que se sujetarán al régimen jurídico contenido en la ley que las crea y, en lo no previsto por ella, al de los establecimientos públicos ${ }^{100}$. Sin embargo, de una primera revisión a las entidades cuyas normas de creación les han asignado la naturaleza jurídica de unidad administrativa especial se observa que esta se ha dado en la administración pública colombiana a entidades de diversos sectores y para distintos fines, abandonándose así el carácter especial que motivó su origen y que un día las justificó.

Por otra parte, en Colombia la reforma administrativa de 1968 dispuso que en el país existen establecimientos públicos encargados esencialmente de atender funciones administrativas y de prestar servicios públicos conforme a las reglas del derecho público ${ }^{101}$. Según Rodríguez, con fundamento en los decretos ley 1222 de 1986 y 1333 de 1986 y en las leyes 128 y 136 de 1994 y 489 de 1998, las personas jurídicas de derecho público "son aquellos organismos de origen estatal, cuyo capital o patrimonio también es estatal o público, a los cuales el ordenamiento jurídico les ha reconocido el carácter de personas jurídicas y que por regla general se encuentran sometidos al derecho público, salvo excepciones legales" ${ }^{\prime 102}$. Podemos entonces definir a los establecimientos públicos como organismos creados o autorizados por la ley, encargados principalmente de ejercer funciones administrativas y de prestar servicios públicos de acuerdo con lo dispuesto para las entidades de derecho público, que reúnen las características de personería jurídica, autonomía administrativa, financiera y patrimonio independiente, constituido con bienes o fondos públicos comunes y el producto de impuestos, rentas contractuales, ingresos propios, tasas o contribuciones de destinación especial, tal como lo señala el artículo 70 de la Ley 489 de 1998. Sin embargo, vale la pena indicar que la autonomía administrativa y financiera predicada en los estándares de 
creación de los establecimientos públicos se ve limitada debido a los diferentes controles que se contemplan en el ordenamiento jurídico ${ }^{103}$. Así mismo, vale la pena recordar que por expresa disposición del artículo 82 de la Ley 489 de 1982 el régimen jurídico de los establecimientos públicos termina siendo un régimen general para la estructura del sector descentralizado de la rama ejecutiva de la administración pública nacional, al aplicarse a un sinnúmero de entidades que lo conforman, ante la ausencia de un régimen legal propio para estas ${ }^{104}$. Además, están sometidos a la coordinación del órgano principal, ministerio o departamento administrativo al cual se encuentran adscritos ${ }^{105}$.

A pesar de que la intención al momento de su creación era su carácter excepcional, la unidad administrativa especial parece haber abandonado la especialidad que un día la identificó, y que incluso fue su razón de ser. Simultáneamente, se ha advertido que, pese a que el régimen de los establecimientos públicos ha terminado aplicándose supletoriamente a un sinnúmero de entidades que, si bien no responden a esta naturaleza jurídica, carecen de un marco legal propio, varias entidades pertenecientes a esta categoría han sido suprimidas o modificadas ${ }^{106}$ en su naturaleza, hasta el punto de que podría

$103 \mathrm{Al}$ respecto podemos señalar los siguientes: el principio de especialidad, que consiste en que no pueden dedicarse a actividades diferentes de aquellas previstas en las normas que los crearon; el principio de afectación, que consiste en que sólo pueden destinar sus recursos a los fines que debe perseguir el organismo según sus estatutos. De otra parte, tenemos el control administrativo antes denominado de tutela, que es el conjunto de mecanismos que tienen por finalidad asegurar que los establecimientos públicos orienten y coordinen sus actividades dentro del contexto de la política general del gobierno y que su presupuesto anual se someta a los trámites y aprobaciones señalados en la Ley Orgánica de Presupuesto, y en concordancia con lo dispuesto en el artículo 105 de la Ley 489 de 1998.

104 "Artículo 82. Unidades administrativas especiales y superintendencias con personería jurídica. Las unidades administrativas especiales y las superintendencias con personería jurídica, son entidades descentralizadas, con autonomía administrativa y patrimonial, las cuales se sujetan al régimen jurídico contenido en la ley que las crea y en lo no previsto por ella, al de los establecimientos públicos".

105 Conforme lo señala la Ley 489 de 1998: "Artículo 6. ${ }^{\circ}$ Principio de coordinación. En virtud del principio de coordinación y colaboración, las autoridades administrativas deben garantizar la armonía en el ejercicio de sus respectivas funciones con el fin de lograr los fines y cometidos estatales. En consecuencia, prestarán su colaboración a las demás entidades para facilitar el ejercicio de sus funciones y se abstendrán de impedir o estorbar su cumplimiento por los órganos, dependencias, organismos y entidades titulares.

Parágrafo. A través de los comités sectoriales de desarrollo administrativo de que trata el artículo 19 de esta Ley y en cumplimiento del inciso 2 del artículo 209 de la C.P. se procurará de manera prioritaria dar desarrollo a este principio de la coordinación entre las autoridades administrativas y entre los organismos del respectivo sector".

Véase LuCiano PAREJO, Lecciones de derecho administrativo, Bogotá: Universidad Externado de Colombia, 2011, p. 186.

106 A continuación se citan algunos ejemplos: el INCODER, creado por el Decreto 1300 de 2003, como un establecimiento público, del orden nacional, adscrito al Ministerio de Agricultura y Desarrollo Rural, con personería jurídica, patrimonio propio y autonomía 
pensarse que la noción de establecimiento público está en crisis (2.1). A esta evolución se acompaña la ausencia de un régimen especial para las agencias estatales nacionales (2.2).

\subsection{De autoridades especiales a autoridades generales: la paradójica evolución de las unidades administrativas especiales}

La noción de unidad administrativa especial data del artículo 1 del Decreto Ley 1050 de 1968, que señala la integración de la rama ejecutiva, y en el inciso 2. ${ }^{\circ}$ menciona: "El Gobierno, previa autorización legal, podrá organizar unidades administrativas especiales para la más adecuada atención de ciertos programas propios ordinariamente de un ministerio o departamento administrativo, pero que, por su naturaleza, o por el origen de los recursos que utilicen, no deban estar sometidos al régimen administrativo ordinario" ${ }^{\prime 107}$.

En esa medida, el objeto de las unidades administrativas especiales lo constituyó una adecuada atención de programas a cargo de ministerios o departamentos administrativos que, por la naturaleza del programa o por los recursos utilizados, estarían sujetos a un régimen administrativo especial, que permitiera una mayor autonomía frente a la administración de los demás recursos públicos. Por ende, en desarrollo de la reforma administrativa de 1968, y

administrativa y financiera, fue suprimido mediante el Decreto 2365 de 2015; el Instituto Nacional de Concesiones, creado en el año 2003 por el Decreto 1800 como un establecimiento público, del orden nacional, adscrito al Ministerio de Transporte, con personería jurídica, patrimonio propio y autonomía administrativa y financiera, fue modificado en su naturaleza para hacer de él una agencia estatal de naturaleza especial, y cambió de denominación por la de Agencia Nacional de Infraestructura, según lo señalado en el Decreto 4165 de 2011.

107 "De conformidad con los términos transcritos, la norma previó la posibilidad de que ciertas competencias administrativas, propias de los ministerios o de los departamentos administrativos, pudieran someterse a un régimen administrativo especial, en razón de circunstancias especiales, por la naturaleza de dichas competencias o por el origen de los recursos". Según el inciso transcrito del artículo $1 .^{\circ}$ del Decreto 1050, las características de las Unidades Administrativas Especiales fueron determinadas como: - La creación legal o por el Gobierno con autorización del legislador. - Para realizar actividades propias de un ministerio o departamento administrativo. - Con competencias administrativas que, por su naturaleza, o por ser financiadas con recursos especiales, o por tratarse de actividades diferentes de las actividades administrativas ordinarias (p. ej., campañas de vacunación, administración de recursos originados en convenios internacionales, ayuda externa pública o privada), pudieran calificarse de especiales. - Y que por ser especiales deben tener un régimen administrativo especial, debiéndose precisar el mismo en el acto de su creación, y en el cual radicaba su carácter de "especiales". A partir de la vigencia del parágrafo transcrito, y con fundamento en el término inicial del mismo, "Además", la tendencia generalizada fue considerar que las unidades administrativas especiales eran otra clase de entidad, diferente a las enumeradas en la mencionada norma como integrantes de la rama ejecutiva, ya como organismos principales o como entes adscritos o vinculados a los principales": SARRIA, ob. cit., 42, p. 240. 
dada la heterogeneidad de las funciones a asumir, se generaron varios modelos organizacionales que respondía más a la naturaleza del objetivo institucional que al origen de los recursos ${ }^{108}$

El artículo 1. ${ }^{\circ}$ del Decreto Ley 1050 de 1968, en lo referente a las unidades administrativas especiales, fue demandado ante la Corte Suprema de Justicia por considerarlo contrario al artículo 76-9 de la Constitución de 1886. Según el actor, "la norma acusada crea un nuevo tipo de repartimiento administrativo denominado unidad administrativa especial que ni es parte de la Rama Ejecutiva del Poder Público, en el sentido constitucional anotado, ni puede calificarse como empresa o instituto descentralizado dentro de la clasificación legal"109. Al respecto, esa corporación judicial precisó el concepto de unidad administrativa especial, tanto desde el punto de vista de las funciones atribuidas como desde el punto de vista de su organización y régimen, señalando que formaban parte de la estructura de los ministerios o de los departamentos administrativos como simples dependencias, y que no estaban adscritas ni vinculadas, ya que eran parte de ellos mismos; se continuó tanto utilizando la calificación de unidades administrativas especiales para entidades ya existentes como creando nuevas sin seguir los criterios y precisiones hechas al respecto por la Corte Suprema de Justicia. "Y de manera general se les reconoció a las unidades administrativas especiales el carácter de personas jurídicas, con lo cual quedaba claro que no formaban parte ni de un ministerio ni de un departamento administrativo, como lo había precisado la jurisprudencia" ${ }^{110}$. Lo cual fue criticado por la doctrina, "en especial en relación con la figura de las superintendencias que fueron calificadas como unidades administrativas especiales y además se les reconoció el carácter de personas jurídicas"111.

En un principio las unidades administrativas especiales fueron creadas como verdaderas dependencias de un ministerio o de un departamento admi-

108 Se les dio el carácter de unidad administrativa especial a las siguientes entidades: "Superintendencia de Notariado y Registro (Decreto 1659 de 1978), Superintendencia de Subsidio Familiar (Ley 25 de 1981), Dirección de Campañas Directas (Decreto 121 de 1976), Juntas Administradoras de Deportes (Decreto 2650 de 1977), Servicio Nacional de Pruebas (Decreto 81 de 1980), Colegios Mayores (Decreto 83 de 1980), Centro Universitario Militar Nueva Granada (Decreto 84 de 1980), Comisión Nacional de Valores (Decreto 831 de 1980), Defensa Civil (Decreto 3398 de 1965)". Igualmente, mediante la Ley $4 .{ }^{a}$ de 1987 se crea el Instituto Tecnológico de Electrónica y Comunicaciones (ITEC), como unidad administrativa especial adscrita a la Empresa Nacional de Telecomunicaciones (Telecom). Así, cabe resaltar que las juntas administradoras seccionales de deportes y el ITEC se crean adscritos a entidades descentralizadas. Ibíd., p. 241.

109 Corte Suprema de Justicia, Sala Constitucional, Sentencia 18 de abril de 1981, exp. 837. 110 Ibíd.

111 Consuelo Sarria, ob. cit., 42, p. 243, citando a Jaime Vidal Perdomo, Derecho administrativo, Bogotá: Biblioteca Banco Popular, 7. ${ }^{a}$ ed. 1980, p. 122 y a Álvaro Tafur Galvis, "Anotaciones sobre la estructura de la Administración Pública colombiana", El derecho administrativo en Latinoamérica II, Bogotá: Ediciones Rosaristas, p. 336. 
nistrativo, cuyo propósito fue evitar que en el futuro funcionaran como ruedas sueltas dentro del aparato administrativo, es decir, para ejercer control sobre las mismas a fin de limitar su independencia, y cuya actividad corresponde a necesidades sobrevinientes dentro de la problemática que debe afrontar dinámicamente la administración moderna. En tal sentido, la Corte Constitucional en la Sentencia C-889 de 2002 establece:

Lo anterior permite concluir en forma diáfana, que las Unidades Administrativas Especiales, tanto desde el punto de vista de las funciones a ellas atribuidas, como desde el punto de vista de su organización y régimen, forman parte de la estructura, bien de los Ministerios, ora de los Departamentos Administrativos, en calidad de simples dependencias. Las entidades cuestionadas, no están pues ni adscritas ni vinculadas a la administración central, son la administración misma ${ }^{112}$.

La Corte Suprema de Justicia, Sala Constitucional, en Sentencia del 14 de febrero de 1985, cambió el criterio expuesto en el año 1981 al señalar: "tratándose de entidades de rango legal, el legislador, ordinario o extraordinario, tiene la potestad organizativa para calificarlos y estructurarlos como lo considere conveniente, sin que tengan que seguirse los criterios generales establecidos por el Congreso al ejercer su función de determinar la estructura de la administración y definir unas determinadas clases de entidades, en cada uno de los sectores, cada una de ellas con sus propios elementos característicos que las diferencia de las demás"113. Dicha jurisprudencia "fomentó la proliferación de unidades administrativas especiales, siempre buscando un mayor grado de autonomía"114.

Con la Constitución de 1991 y con el fin de adecuar la organización administrativa a las nuevas exigencias constitucionales se expidió la Ley 489 de $1998^{[115]}$, en la cual se confirma el fenómeno jurídico sobre la noción de unidad administrativa especial en el derecho público colombiano, regulando de forma genérica las unidades administrativas especiales con o sin personería jurídica, con lo cual la ley recogió la realidad en relación con ellas y con la interpretación de la jurisprudencia en cuanto a la potestad organizativa del legislador. Vemos entonces que la Ley 489 de 1998 en sus artículos 67 y 82 diferenció las dos formas que se pueden dar a las unidades administrativas especiales ${ }^{116}$;

112 Corte Constitucional, Sentencia C-889 de 2002, disponible en: http://www.corteconstitucional.gov.co/relatoria/2002/C-889-02.htm

113 Consuelo Sarria, ob. cit., 42, p. 243, citando a la Corte Suprema de Justicia, Sala Constitucional, Sentencia del 14 de febrero de 1985, exp. 1244.

114 Ibíd., p. 243.

115 Artículo 38 de la Ley 489 de 1998 ; v. supra nota 20.

116 "Artículo 67.- Organización y funcionamiento de Unidades Administrativas Especiales. Las unidades administrativas especiales son organismos creados por la ley, con la autonomía administrativa y financiera que aquella les señale, sin personería jurídica, que cumplen funciones administrativas para desarrollar o ejecutar programas propios de un ministerio o depar- 
las que no tengan personería jurídica serán del nivel central, y las que tengan personería jurídica serán entidades descentralizadas, de la rama ejecutiva del poder público; pero tanto las unas como las otras ejecutan programas propios de un ministerio o departamento administrativo.

Así las cosas, surgen dos interrogantes, el primero consistente en saber si las unidades administrativas especiales, con independencia de que se les otorgue o no la personalidad jurídica, dejaron de tener ese carácter especial del que gozaban en función de su naturaleza u origen de los recursos, y el otro que apunta a establecer si en la actualidad están sometidas a un régimen propio.

Al respecto, Sarria sostiene:

... el concepto de unidad administrativa especial no es claro, y por ello se ha utilizado para darle[s] ese calificativo a diferentes entidades dentro de la administración pública, sin rigor jurídico y siempre buscando un mayor grado de autonomía en relación con los organismos centrales de la administración. Al efecto puede observarse cómo en la reforma administrativa de 2011, hecha por el Gobierno con fundamento en las facultades otorgadas por la Ley 1444 de 2011, se les dio el carácter de unidades administrativas especiales a 23 entidades de la administración, 5 sin personería jurídica y 18 con personería jurídica, estas últimas, por expresa definición legal son entidades descentralizadas, lo que confirma la tendencia de buscar mayor autonomía ${ }^{117}$.

Ante este panorama se presenta la pérdida del carácter especial de las unidades administrativas especiales que permitía a la administración contar con un instrumento en la ejecución de un determinado programa ministerial o de un departamento administrativo, para ubicarse como una institución más. Además, tampoco poseen un régimen propio en la medida en que el artículo 82 de la Ley 489 de 1998 contempla que se sujetarán al régimen que las crea y en lo no previsto en él, al de los establecimientos públicos.

Considerando lo expuesto, es posible señalar que la figura de unidad administrativa especial se ha desarrollado en la administración pública colombiana, en diversos sectores y para distintos fines, como lo advirtió la Corte Constitucional en sentencia C-889 de 2002, en la que se hizo referencia a que esta noción ha sido utilizada en distintos campos como el transporte aéreo (Unidad Administrativa Especial de Aeronáutica Civil), la contabilidad general de la Nación (Contaduría General de la Nación) y la regulación de servicios públicos domiciliarios (Comisión de Regulación de Agua Potable y Saneamiento

tamento administrativo". "Artículo 82.- Unidades administrativas especiales y superintendencias con personería jurídica. Las unidades administrativas especiales y las superintendencias con personería jurídica, son entidades descentralizadas, con autonomía administrativa y patrimonial, las cuales se sujetan al régimen jurídico contenido en la ley que las crea y en lo no previsto por ella, al de los establecimientos públicos".

117 Consuelo Sarria, ob. cit., 42, p. 245 
Básico), entre otros. ¿Estamos entonces en presencia de una noción jurídica similar a la de autoridad administrativa?

Si bien la Ley 489 de 1998 contempló diferentes formas de organización y funcionamiento para las unidades administrativas especiales, no se señalaron unas características y estructura organizacional que le dieran una fisonomía propia, haciendo muy difícil su caracterización y clasificación. Incluso, a pesar de que ciertas unidades administrativas especiales gozan de un régimen especial, como es el caso de la Dirección de Impuestos y Aduanas Nacionales (DIAN), o de garantías de autonomía constitucional, como el Banco de la República, que les permitiría ser más eficientes en su gestión, está claro que hasta tanto no se les fije un régimen especial claramente definido, materialmente seguirán careciendo de identidad propia, desvirtuándose de esta manera el carácter especial que justificó su creación y convirtiéndose en la práctica en una entidad a la cual por expresa disposición legal en lo no previsto en la ley que las crea le es aplicable el régimen general de los establecimientos públicos ${ }^{118}$.

Esta situación se ilustra en un cuadro comparativo entre las características de las unidades administrativas especiales sin y con personería jurídica y los establecimientos públicos, en el cual se demuestra que las diferencias, cuando hacen parte del sector descentralizado de la rama ejecutiva, serían meramente funcionales:

\begin{tabular}{ccc}
\hline $\begin{array}{c}\text { Unidad Administrativa } \\
\text { Especial (Sector Central) }\end{array}$ & $\begin{array}{c}\text { Unidad Administrativa } \\
\text { Especial (Sector Descentrali- } \\
\text { zado por Servicios) }\end{array}$ & $\begin{array}{c}\text { Establecimiento Público } \\
\text { (Sector Descentralizado por } \\
\text { Servicios) }\end{array}$ \\
\hline Creadas por ley & $\begin{array}{c}\text { Creadas por ley o con su } \\
\text { autorización }\end{array}$ & $\begin{array}{c}\text { Creados por ley, ordenanza } \\
\text { o acuerdo }\end{array}$ \\
\hline $\begin{array}{c}\text { Marco jurídico: derecho } \\
\text { público }\end{array}$ & $\begin{array}{c}\text { Marco jurídico: derecho } \\
\text { público }\end{array}$ & $\begin{array}{c}\text { Marco jurídico: derecho } \\
\text { público }\end{array}$ \\
\hline $\begin{array}{c}\text { Autonomía administrativa } \\
\text { y financiera, según acto de } \\
\text { creación }\end{array}$ & $\begin{array}{c}\text { Autonomía administrativa, } \\
\text { financiera y patrimonial }\end{array}$ & $\begin{array}{c}\text { Autonomía administrativa y } \\
\text { financiera, patrimonio inde- } \\
\text { pendiente }\end{array}$ \\
\hline Sin personería jurídica & Personería jurídica & Personería jurídica \\
\hline $\begin{array}{c}\text { Adscritas a ministerio o de- } \\
\text { partamento administrativo }\end{array}$ & $\begin{array}{c}\text { Adscritas a un ministerio o a } \\
\text { un departamento administra- } \\
\text { tivo en el orden nacional }\end{array}$ & $\begin{array}{c}\text { Adscritas a un ministerio o a } \\
\text { un departamento administra- } \\
\text { tivo en el orden nacional }\end{array}$ \\
\hline $\begin{array}{c}\text { Funciones administrativas } \\
\text { propias de un ministerio o } \\
\text { departamento administrativo }\end{array}$ & $\begin{array}{c}\text { Funciones administrativas } \\
\text { propias de un ministerio o } \\
\text { departamento administrativo }\end{array}$ & $\begin{array}{c}\text { Funciones administrativas } \\
\text { y prestación de servicios } \\
\text { públicos }\end{array}$ \\
\hline
\end{tabular}

118 Al respecto la Ley 489 de 1998 dispone: "Artículo 82.- Unidades administrativas especiales y superintendencias con personería jurídica. Las unidades administrativas especiales y las superintendencias con personería jurídica, son entidades descentralizadas, con autonomía administrativa y patrimonial, las cuales se sujetan al régimen jurídico contenido en la ley que las crea y en lo no previsto por ella, al de los establecimientos públicos". 
Una vez revisada la evolución de la noción de unidad administrativa especial en Colombia y habiéndose determinado que el carácter especial que históricamente ha justificado su existencia no es tal y, por ende, que poseen un carácter más general, ello permite comprender el entorno jurídico colombiano en el que han surgido las agencias estatales, tema que se aborda a continuación.

\subsection{La ausencia de un régimen especial para el caso de las agencias nacionales}

El objetivo de la reforma administrativa de 2011, según sus autores, era fortalecer las instituciones para lograr la eficiencia administrativa y un Estado más eficaz. Para ello, mediante la Ley 1444 de 2011 se otorgaron facultades extraordinarias al Presidente de la República ${ }^{19}$. Surgen así en la estructura de la administración pública nacional las agencias estatales ${ }^{120}$, habiéndoles

119 Las facultades otorgadas en el artículo 18 fueron para:

a) "Crear, escindir, fusionar y suprimir, así como determinar la denominación, número, estructura orgánica y orden de precedencia de los departamentos administrativos;

b) Determinar los objetivos y la estructura orgánica de los Ministerios creados por disposición de la presente ley, así como la integración de los sectores administrativos respectivos; c) Modificar los objetivos y estructura orgánica de los Ministerios reorganizados por disposición de la presente ley, así como la integración de los sectores administrativos respectivos;

d) Reasignar funciones y competencias orgánicas entre las entidades y organismos de la Administración Pública Nacional y entre estas y otras entidades y organismos del Estado,

e) Crear, escindir y cambiar la naturaleza jurídica de los establecimientos públicos y otras entidades u organismos de la rama ejecutiva del orden nacional,

f) Señalar, modificar y determinar los objetivos y la estructura orgánica de las entidades u organismos resultantes de las creaciones, fusiones o escisiones y los de aquellas entidades u organismos a los cuales se trasladen las funciones de las suprimidas, escindidas, fusionadas o transformadas, y de la Agencia Nacional para la Defensa Jurídica del Estado;

g) Crear las entidades u organismos que se requieran para desarrollar los objetivos que cumplían las entidades u organismos que se supriman, escindan, fusionen o transformen, cuando a ello haya lugar;

h) Determinar la adscripción o la vinculación de las entidades públicas nacionales descentralizadas;

i) Realizar las modificaciones presupuestales necesarias para financiar los gastos de funcionamiento e inversión necesarios para el cumplimiento de las funciones que se asignen a las entidades creadas, escindidas, suprimidas, fusionadas o reestructuradas en desarrollo de las facultades otorgadas por la presente ley;

j) Crear los empleos en la planta de personal de la Fiscalía General de la Nación que se requieran para asumir las funciones y cargas de trabajo que reciba como consecuencia de la supresión o reestructuración del DAS. En los empleos que se creen se incorporarán los servidores públicos que cumplan estas funciones y carga de trabajo en la entidad reestructurada o suprimida, de acuerdo con las necesidades del servicio. Igualmente, se realizarán los traslados de recursos a los cuales haya lugar".

120 Ver Anexo 2, Entidades denominadas Agencias que tienen naturaleza de Unidad Administrativa Especial y Agencias Estatales de Naturaleza Especial. 
dado a la mayoría de ellas la naturaleza jurídica de unidades administrativas especiales, noción esta que responde a un concepto amplio, que vimos rige actualmente, y a otras, la de agencias estatales de naturaleza especial ${ }^{121}$, sin indicar su significado y alcance. Por lo tanto, es necesario revisar a qué alude dicha naturaleza y si se les dotó de un régimen especial.

Recordemos que, tal y como se mencionó en la introducción, son justamente estas entidades, denominadas por los órganos legislativo y ejecutivo como agencias estatales de "naturaleza especial", las que constituyen el objeto de estudio de este trabajo de investigación, ya que respecto de las otras agencias su naturaleza jurídica es la de unidad administrativa especial en el sentido amplio, pero no menos confuso, que ha adquirido esta noción.

$\mathrm{Al}$ respecto debe mencionarse que las normas de creación o transformación de estas agencias no precisan el contenido material de su naturaleza especial ${ }^{122}$. Sin embargo, es posible señalar unas características generales dentro de las que se destaca que son del orden nacional, pertenecen al sector descentralizado, están adscritas a un ministerio o forman parte de un sector administrativo, tienen personería jurídica, autonomía patrimonial, autonomía técnica y autonomía administrativa y financiera ${ }^{123}$, características que no son especiales respecto de otras autoridades administrativas, pues también son predicables de las unidades administrativas especiales con personería jurídica (muchas también denominadas agencias) y de los establecimientos públicos, como quedó demostrado en páginas anteriores; siendo posible afirmar entonces que estas agencias estatales de naturaleza especial carecen de una identidad propia, y por ende no constituyen una categoría distinta de las que tradicionalmente han integrado la administración pública colombiana. Esta situación parece ubicarlas por tanto como autoridades administrativas que aluden funcionalmente a unidades administrativas especiales y orgánicamente a establecimientos públicos.

Tampoco se trata de las entidades que el artículo 40 de la Ley 489 de 1998 relaciona como organismos estatales sujetos a un régimen especial otorgado por la Constitución Política (Banco de la República, entes universitarios autónomos, corporaciones autónomas regionales y demás organismos con régimen especial contemplado en la Constitución), que como tales se sujetan a las disposiciones que para ellos establecen las respectivas leyes.

121 Agencias estatales de naturaleza especial: la Agencia Nacional de Minería (Decreto 4134 de 2011), la Agencia Nacional de Hidrocarburos (Decreto 4137 de 2011), la Agencia Nacional de Infraestructura (Decreto 4165 de 20011) y la Autoridad Nacional de Televisión (Ley 1507 de 2012). Al respecto, vale la pena indicar que la naturaleza de algunas de estas agencias de naturaleza especial, antes de la reforma, era la de unidad administrativa especial, tratándose de la Agencia Nacional de Hidrocarburos, y de establecimiento público, como es el caso de la Agencia Nacional de Infraestructura.

122 Ver decretos, 4134, 4137 y 4165 de 2011 y Ley 1507 de 2012.

123 Ibíd. 
De otra parte, aun cuando el numeral 2 del artículo 50 de la Ley 489 de 1998 dispone que en los actos de creación de un organismo o entidad administrativa se debe determinar, entre otros aspectos, su régimen jurídico, en los decretos leyes de creación o transformación de estas agencias, salvo el caso de la Autoridad Nacional de Televisión previsto por la Ley 1507 de 2012, no se indica expresamente un régimen aplicable ${ }^{124}$.

Ante la ausencia de la mención a un régimen especial para las agencias estatales de naturaleza especial y considerando que se trata de entidades creadas o autorizadas por la ley, concebidas como entidades descentralizadas que ejercen funciones administrativas, prestan servicios públicos y reúnen las características generales antes mencionadas, puede señalarse que el régimen que se les termina aplicando es el de derecho público contenido en sus normas de creación y, en lo no previsto en ellas, el de las normas generales cuyo ámbito de aplicación ha sido determinado por el legislador mediante el criterio orgánico, como al efecto ocurre con la Ley 80 de 1993 (Estatuto General de Contratación de la Administración Pública), en cuyo literal a) del artículo $2 .^{\circ}$ se contempla que lo dispuesto en ella se aplica a las entidades estatales, cualquiera sea la denominación que ellas adopten; con la Ley 1437 de 2011, en cuyo artículo 2. ${ }^{\circ}$ se dispuso que las normas del Código de Procedimiento Administrativo se aplicarán a todos los organismos y entidades que conforman las ramas del poder público en sus distintos órdenes, sectores y niveles, a los órganos autónomos e independientes del Estado y a los particulares, cuando cumplan funciones administrativas; y en el Estatuto Orgánico del Presupuesto (Decreto 111 de 1996), en cuyo artículo $4 .^{\circ}$ se previó que, para efectos presupuestales, a las personas jurídicas públicas del orden nacional cuyo patrimonio esté constituido por fondos públicos y no sean empresas industriales y comerciales del Estado o sociedades de economía mixta o asimiladas a estas por la ley de la República, se les aplicarán las disposiciones que rigen los establecimientos públicos del orden nacional.

Al respecto sobre las agencias de naturaleza especial, Rodríguez, señala:

En consecuencia, consideramos que en materia de actos serán aplicables las normas generales de los actos administrativos ya que la función que ejerce es de naturaleza administrativa. Respecto de la contratación, teniendo en cuenta que no se consagran normas especiales, de acuerdo con los artículos 1 y 2 de la ley 80 de 1993, será aplicable el Estatuto General de Contratación de la Administración Pública. Finalmente, en materia presupuestal, dada su naturaleza jurídica y la inexistencia de normas especiales, de conformidad con el artículo $4 .{ }^{\circ}$ del decreto-ley 111 de

124 En este sentido, el parágrafo 1 del artículo $2 .^{\circ}$ de la Ley 1507 de 2012 prevé que "para efectos de los actos, contratos, funcionarios, regímenes presupuestal y tributario, sistemas de controles y en general el régimen jurídico aplicable, la ANTV se asimila a un establecimiento público del orden nacional, salvo lo previsto en la presente ley". 
1996, la Agencia estará sometida a las reglas de los establecimientos públicos del orden nacional ${ }^{125}$.

Ante este panorama, como se indicó al inicio, en una segunda entrega se estudiará si las agencias estatales de naturaleza especial en Colombia son diferentes funcional y estructuralmente de otras categorías de organismos y entidades que integran la administración pública del orden nacional.

Como consideraciones finales de esta primera entrega pueden señalarse las siguientes:

- Ante la ausencia de una tipificación conceptual propia en el derecho público colombiano, podría indicarse que la de agencia es una noción que no alude a una nueva categoría de órgano de la administración, sino que es un término que designa a cualquier autoridad administrativa.

- La intención al momento de la creación de las unidades administrativas especiales era su carácter excepcional, sin embargo, parece haberse abandonado esta especialidad que un día las caracterizó y que incluso fue su razón de ser. Simultáneamente se ha advertido que, pese a que el régimen de los establecimientos públicos ha terminado aplicándose supletoriamente a un sinnúmero de entidades que, si bien no responden a esta naturaleza jurídica, carecen de un marco legal propio, varias entidades pertenecientes a esta categoría han sido suprimidas o modificadas en su naturaleza, hasta el punto de que podría pensarse que la noción de establecimiento público está en crisis. A esta evolución se acompaña la ausencia de un régimen especial para las agencias estatales nacionales.

- Las normas de creación o transformación de las agencias no precisan el contenido material de su naturaleza especial. Sin embargo, es posible señalar unas características generales, dentro de las que se destacan que son del orden nacional, pertenecen al sector descentralizado, están adscritas a un ministerio o forman parte de un sector administrativo, poseen personería jurídica, autonomía patrimonial, autonomía técnica y autonomía administrativa y financiera, características que no son especiales respecto de otras autoridades administrativas, pues también son predicables de las unidades administrativas especiales con personería jurídica (muchas también denominadas agencias) y de los establecimientos públicos.

- Ante la ausencia de la mención a un régimen especial para las agencias estatales de naturaleza especial y considerando que se trata de entidades creadas o autorizadas por la ley, concebidas como entidades descentralizadas que ejercen funciones administrativas, prestan servicios públicos y reúnen las características generales antes mencionadas, puede señalarse que el régimen que se les termina aplicando es el de derecho público contenido en sus normas de 
creación y, en lo no previsto en ellas, en las normas generales cuyo ámbito de aplicación ha sido determinado por el legislador mediante el criterio orgánico.

- Dentro del tipo de agencias fruto de la reforma a la administración pública nacional llevada a cabo de 2011 a 2013 se concibió a la Agencia Nacional de Infraestructura como una agencia nacional estatal de naturaleza especial, del sector descentralizado de la rama ejecutiva del orden nacional, con personería jurídica, patrimonio propio y autonomía administrativa, financiera y técnica, adscrita al Ministerio de Transporte, a la cual se le encomendó: "planear, coordinar, estructurar, contratar, ejecutar, administrar y evaluar proyectos de concesiones y otras formas de Asociación Público Privada (APP), para el diseño, construcción, mantenimiento, operación, administración y/o explotación de la infraestructura pública de transporte en todos sus modos y de los servicios conexos o relacionados y el desarrollo de proyectos de asociación público privada para otro tipo de infraestructura pública cuando así lo determine expresamente el Gobierno Nacional respecto de infraestructuras semejantes a las enunciadas en este artículo, dentro del respeto a las normas que regulan la distribución de funciones y competencias y su asignación". Esta Agencia ha sido reconocida por la publicación inglesa $P_{3}$ Bulletin como la mejor agencia gubernamental de 2014 de asociaciones público privadas (APP), por su liderazgo y eficiencia en incentivar la participación privada en la construcción de proyectos de infraestructura para los ciudadanos.

\section{BIBLIOGRAFÍA}

\section{ObRAS GENERALES y ESPECIALIZADAS}

David, RenÉ. Le droit anglais, Paris: PUF, 10. ${ }^{a}$ ed., 2003.

IBÁÑEZ, JoRGE ENRIQUE. Estudios de derecho constitucional y administrativo, Bogotá: Legis y Universidad Sergio Arboleda, 2007.

Legrand, PieRre. Le droit comparé, Paris: PUf, 1999.

Montaña, Alberto. Fundamentos de derecho administrativo, Bogotá: Universidad Externado de Colombia, 2010.

Ramírez Cleves, Gonzalo Andrés. Pobreza, globalización y derecho, Bogotá: Universidad Externado de Colombia, 2009.

RodrígueZ, Libardo. Estructura del poder público en Colombia, Bogotá: Temis, 2015.

Santofimio Gamboa, Jaime. Tratado de derecho administrativo, t. I, 3. ${ }^{a}$ ed., Bogotá: Universidad Externado de Colombia, 2013. 
Vidal Perdomo, Jorge. La reforma constitucional de 1968 y sus alcances. Bogotá: Universidad Externado de Colombia, 1970.

Younes Moreno, Diego. El nuevo Estatuto de Organización y Funcionamiento de la Administración Pública: análisis y comentarios de la Ley 489 de 1998, Bogotá: Ediciones Jurídicas Gustavo Ibáñez, 1999.

Younes Moreno, Diego. Las reformas del Estado y de la Administración Pública, Bogotá: Instituto de Estudios del Ministerio Público, 2012.

\section{Artículos y CONTRibuciones}

Auby, Jean Bernard. "Droit administratif et democratie", en Regulation économique et démocratie, dir. Martne Lombard, Paris: Dalloz, 2006.

Boto, Alejandra. "La agencia como forma organizativa de optimización de servicios públicos. Pasado, presente y futuro en una España en crisis", Revista digital de Derecho Administrativo, n. ${ }^{\circ}$ 13, enero-junio, Universidad Externado de Colombia, pp. 45-61, disponible en: http://revistas.uexternado.edu.co/index.php/Deradm/ article/view/4186/4809

Bresser Pereira, Luiz Carlos. "La reforma del Estado de los años noventa: lógica y mecanismos de control", en Desarrollo Económico - Revista de Ciencias Sociales, Buenos Aires, vol. 38, n. ${ }^{\circ}$ 150, julio-septiembre 1998, pp. 517-550, disponible en: http:// pendientedemigracion.ucm.es/centros/cont/descargas/documento24210.pdf

Córdova, Eduardo y Mayorga, Fernando. "Gobernabilidad y Gobernanza en América Latina", [Consulta 25/02/2016], disponible en: http://www.institut-gouvernance. org/docs/ficha-gobernabilidad.pdf

Cosculluela Montaner, Luis Manuel. "Las agencias estatales", Revista Española de Control Externo, 2006, pp. 29-53.

Gama, Claire Launay. "El uso del concepto de gobernanza o/y gobernabilidad en Colombia", Cuaderno Usos y desafíos del concepto de gobernanza en Colombia, Instituto de Investigación y Debate sobre la Gobernanza, [Consulta 25/02/2016], disponible en: http://www.institut-gouvernance.org/es/analyse/fiche-analyse-236.html

GÓmEZ, LiLianA. "El buen gobierno: paradigmas y perspectivas políticas", [Consulta 26/02/2016], disponible en: http://ridum.umanizales.edu.co:8080/xmlui/bitstream/ handle/6789/1860/Art\%C3\%ADculoBUENGOBIERNO\%20revisado.pdf? sequence $=1$

González Salas, Édgar. "La reforma de la administración pública 2002-2009", Revista Política Colombiana, octubre-diciembre 2009, pp. 29-32, [Consulta 6/3/2016], disponible en: http://politicacolombiana.net/pdfs/2edicion/ articulo02.pdf 
GOnZÁLEZ SALAS, ÉDGAR. "La reforma al Estado: bondades y limitaciones", razonpublica.com, febrero, 2012, (en línea) [Consulta 6/3/2016], disponible en: http://www. razonpublica.com/index.php/politica-y-gobierno-temas-27/2707-la-reforma-alestado-bondades-y-limitaciones.html

IbÁÑEZ, Jorge EnRIQUe. "Colombia: un Estado en reforma permanente", Revista Ópera, 2002, pp. 5-21.

Lombard, Martine. "Régulateurs indépendants, mode d'emploi", en Régulation économique et démocratie, Paris: Dalloz, 2006.

Molina, Carlos Mario y Cerón, Pilar. "Primeras reflexiones acerca del contenido normativo de la Ley 489 de 1998", Revista Estudios Socio-Jurídicos, Universidad del Rosario, vol. 6, n. ${ }^{\circ}$ 2, julio-diciembre, 2004, pp. 145-180, [Consulta 1/3/2016], disponible en: http://www.redalyc.org/articulo.oa?id=73360205

Montaña, Alberto. "La incorporación de agencias en la estructura administrativa colombiana del orden nacional. Una confrontación axiológica de dos modelos organizacionales de la administración pública", Revista digital de Derecho Administrativo, n. ${ }^{\circ}$ 13, enero-junio, Universidad Externado de Colombia, pp. 27-43, disponible en: http://revistas.uexternado.edu.co/index.php/Deradm/article/view/4185/4808.

Orjuela, Luis JAVIER. "El Estado colombiano en los noventa: entre la legitimidad y la eficiencia", Revista de Estudios Sociales, Universidad de los Andes, (en línea), pp. 56-60, [Consulta 25/02/2016], disponible en: http://res.uniandes.edu.co/view. php/28/index.php?id=28

Pacheco, Ronald. "La Autoridad Nacional de Televisión, cuna agencia estatal independiente?", Revista digital de Derecho Administrativo, n. ${ }^{\circ} 13$, enero-junio, Universidad Externado de Colombia, 2015, pp. 63-98, disponible en: http://revistas.uexternado. edu.co/index.php/Deradm/article/view/4187/4810

Palacios Lleras, Andrés. "Introducción al Análisis Económico del Derecho Administrativo", Revista de Derecho Público, Universidad de Los Andes, n. ${ }^{\circ} 22$, febrero, 2009, [Consulta 11/05/2016], disponible en: https://derechopublico.uniandes.edu. co/components/com_revista/archivos/derechopub/pub101.pdf

Rincón CóRdobA, Jorge IvÁn. "Límites orgánicos de la responsabilidad del Estado", en XVI Jornadas Internacionales de Derecho Administrativo, Bogotá: Universidad Externado de Colombia, 2015.

Rincón, JoRge IVÁn. "Presentación", Revista digital de Derecho Administrativo, n. ${ }^{\circ}$ 13, enerojunio, Universidad Externado de Colombia, pp. 9-13, disponible en: http://revistas. uexternado.edu.co/index.php/Deradm/article/view/4183/4806

Rodríguez, Elizabeth. "Reformas de la administración pública 2011 en Colombia: por un Estado más eficiente", Revista del CLAD sobre la Reforma del Estado y de la Admi- 
nistración (en línea), pp. 1-10, [Consulta 25/02/2016], disponible en: http://www. dgsc.go.cr/dgsc/documentos/cladxvii/rodriel.pdf

Sarria, Consuelo. "¿Las agencias son unidades administrativas especiales?", Revista digital de Derecho Administrativo, n. ${ }^{\circ}$ 13, enero-junio, Universidad Externado de Colombia, 2015, pp. 237-252, disponible en: http://revistas.uexternado.edu.co/index. php/Deradm/article/view/4193/4816

Tafur Galvis, Álvaro. "Anotaciones sobre la estructura de la Administración Pública colombiana", en El derecho administrativo en Latinoamérica II, Bogotá: Ediciones Rosaristas.

Universidad de Antioquia. "Antecedentes y contexto del surgimiento de la Constitución de 1991", [Consulta 26/02/2016], disponible en: http://docencia.udea. edu. $\mathrm{co} /$ derecho/constitucion/antecedentes.html

Vidal Perdomo, Jorge. "Reforma Administrativa de 1968: antecedentes, teoría de la organización y funcionamiento, sus principales consecuencias", Vniversitas, Bogotá, 2004, disponible en: http://revistas.javeriana.edu.co/index.php/vnijuri/ article/view/14731/11881

Weber, Max. "Burocracia", [Consulta 11/05/2016], disponible en: http://mba pensamiento.blogspot.com.co/2011/08/burocracia-max-weber.html

Weber, Max. "Burocracia estatal, Conceptos de Ciencia Política, Administración, Soberanía", [Consulta 11/05/2016], disponible en: http://historiaybiografias.com/ ciencia_politica3/

\section{Monografías Y TESIS DE DOCTORADO}

Palacios Amaya, Aleyda. "Trascendencia del concepto de agencia estatal en la estructura del poder público colombiano", 2015. tutor: J. Sandoval Carranza, [Consulta 2/3/2016], disponible en: http://repository.unimilitar.edu.co/bitstream/10654/ 13891/2/ TRABAJO\% 20DE\% 20GRADO\%20TRASCENDENCIA\%20DEL\%20 CONCEPTO\%20 DE\%20AGENCIA\%20ESTATAL\%20EN\%20LA\%20ESTRUCTURA\%20DEL\%20PODER\%20 P\%C3\%9ABLICO\%20COLOMBIANO.pdf

ZÁrate, Aníbal. L'indépendence des autorités de concurrence, Analyse comparative Colombie, France, États-Unis, thèse de doctorat, Université Paris II, Panthéon-Assas, dir. Martine Lombard.

\section{INFORMES Y DOCUMENTOS DE INTERÉS}

Alberdi, Jokin. "Diccionario de la Acción Humanitaria y Cooperación al Desarro1lo", [Consulta 23/08/2015], disponible en: http://www.dicc.hegoa.ehu.es/listar/ mostrar/24, Acepciones de Buen Gobierno. 
Agencia Nacional de Hidrocarburos. "Consolidación institucional del sector de hidrocarburos. Transformación de la Agencia Nacional de Hidrocarburos", Estudio Técnico, Bogotá, noviembre de 2011.

Avezuela, Jesús. "Agencias. El ejemplo norteamericano", disponible en: http://www. funciva.org/uploads/ficheros_documentos/1225902539_agencias.pdf

Bresser Pereira, Luiz Carlos. Lecturas sobre el Estado y las políticas públicas: retomando el debate de ayer para fortalecer el actual, Buenos Aires: CLAD.

Comisión De Infraestructura. "Informe", Bogotá, octubre de 2012.

Congreso de la República. Gaceta del Congreso, 17 de agosto de 2010. "Exposición de Motivos - Ley 1444 de 2011". Proyecto de Ley n.o 053 de 2010 Cámara, Bogotá.

Consejo Científico del Clad. "Una Nueva Gestión Pública para América Latina", [Consulta 26/02/2016], disponible en: http://old.clad.org/investigaciones/ investigaciones-concluidas/documento-del-consejo-cientifico-del-clad-una

Departamento Nacional de Planeación. "Documento conpes 3248", 20 de octubre de 2003.

Departamento Nacional de Planeación. "Manual de Clasificación Presupuestal del Gasto de Inversión", 21 de septiembre de 2011, disponible en: https://colaboracion. dnp.gov.co/CDT/Inversiones\%20y\%20finanzas\%20pblicas/Manual\%20de\%20 clasificaci\%C3\%B3n\%20para\%202012\%20v\%2012\%2021\%20septiembre\%20 (2).pdf

Departamento Nacional de Planeación. "Bases del Plan Nacional de Desarrollo, Capítulo VII, Soportes transversales de la prosperidad democrática", [Consulta 26/02/2016], disponible en: http://colaboracion.dnp.gov.co/ CDT/PND/8C.\%20 Cap\%C3\%ADtulo\%20viI.pdf

Ingeominas, Instituto Colombiano de Geología y Minería, Universidad Nacional de Colombia. "Estudio Técnico para la reestructuración de Ingeominas", abril de 2012.

Instituto Nacional de Concesiones, Unión Temporal Stratco Consultores Asociados - Nexus Banca de Inversión. "Estudio Técnico y propuesta para la reestructuración del Instituto Nacional de Concesiones en la Agencia Nacional de Infraestructura", Bogotá, diciembre de 2011.

Organización para la Cooperación y el Desarrollo Económico (ocde). "Análisis y Recomendaciones. Colombia: la implementación del buen gobierno", 2014, disponible en: http://cdim.esap.edu.co/BancoMedios/ Documentos\%20PDF/colombia\%20la\%20implementacion\%20del\%20buen\%20gobierno.pdf 
Pardo, María del Carmen. De la Administración Pública a la Gobernanza, Reforma a la Gestión Pública, [Consulta 26/02/2016], disponible en: http://www.iapqroo.org. $\mathrm{mx} /$ website/biblioteca/DE\%20LA\%20ADMINISTRACION\%20PUBLICA\%20A\%20LA\%20 GOBERNANZA.pdf

http://www.ani.gov.co/article/ani-la-mejor-agencia-gubernamental-de-asociacionespublico-privadas-en-america-en-2014-13822

JURISPRUDENCIA

\section{Corte Constitucional. Sentencias}

C-50 de 1994. Disponible en: http://www.corteconstitucional.gov.co/ relatoria/1994/C-050-94.htm

C-401 de 2001. Disponible en: http://corteconstitucional.gov.co/relatoria/2001/C-401-01. htm

C-827 de 2001. Disponible en: http://www.corteconstitucional. gov.co/ relatoria/2001/c-827-01.htm

C-1051 de 2001. Disponible en: http://www.corteconstitucional.gov.co/ relatoria/2001/C-1051-01.htm

C-889 de 2002. Disponible en: www.corteconstitucional.gov.co

C-205 de 2005 Disponible en: http://www.alcaldiabogota.gov.co/sisjur/normas/ Norma1.jsp?i $=48828$

C-736 de 2007. Disponible en:

C-910 de 2007. Disponible en: http://corteconstitucional.gov.co/ RELATORIA/ 2007/C-910-07.htm

C-816 de 2011. Disponible en:

\section{Resoluciones}

1175 de 2013 de la Autoridad Nacional de Televisión. 


\title{
ANEXOS
}

ANEXO N. ${ }^{\circ} 1$

\section{ACEPCIONES DE BUEN GOBIERNO}

\author{
JokIn AlBERDi
}

Diccionario de la Acción Humanitaria y Cooperación al Desarrollo

"Forma de ejercicio del poder en un país caracterizada por rasgos como la eficiencia, la transparencia, la rendición de cuentas, la participación de la sociedad civil y el estado de derecho, que revela la determinación del gobierno de utilizar los recursos disponibles a favor del desarrollo económico y social. El concepto de buen gobierno (good governance) se ha difundido ampliamente en la literatura sobre estudios del desarrollo desde principios de los años 90 a raíz de un estudio realizado por el BANCO Mundial (World Bank, 1992) sobre la crisis y el crecimiento sostenido en el Africa Subsahariana y la importancia del mencionado buen gobierno en el desarrollo económico. Según el estudio, el fracaso en muchos países africanos de las políticas de ajuste estructural se habría debido precisamente a la ausencia de aquél, esto es, al mal gobierno (poor governance) reinante, que habría dificultado las necesarias inversiones extranjeras. Este mal gobierno se caracteriza por problemas como: a) la falta de responsabilidad y de una rendición de cuentas de los poderes públicos; b) la falta de transparencia ${ }_{i}$ c) la escasa capacidad de previsión de los políticos y funcionarios; y d) la ausencia del Estado de derecho. En consecuencia, desde los 90 la mayoría de los donantes de cooperación al desarrollo han insistido en la necesidad del buen gobierno en los países receptores. De este modo, después de acabada la Guerra Fría, que determinaba una ayuda internacional en función del alineamiento de bloques, en la actualidad el buen gobierno se ha convertido en uno de los principales criterios políticos de CONDICIONALIDAD para la concesión de aquélla. A su vez, diferentes organismos internacionales han procedido a llevar a cabo diversos programas a favor del buen gobierno en los países en desarrollo. Ahora bien, tal vez por su contenido netamente político, la noción de buen gobierno presenta significados no plenamente coincidentes para diferentes instancias. a) Las instituciones ubicadas en el llamado Consenso de Washington (gobierno de los EE.uU., FMI (Fondo Monetario Internacional) y BANCO MUNDIAL), aunque con algunas diferencias, proponen agendas de buen gobierno centradas no tanto en el tipo de régimen político, sino más bien en determinadas características del proceso de gobernabilidad, como son la rendición de cuentas, la transparencia y el estado de derecho. Ahora bien, mientras el gobierno norteamericano suele hacer más hincapié en temas relacionados con la democracia y los derechos civiles, el FMI se ha centrado en la reducción de los gastos militares, en tanto que el Banco Mundial ha manejado una agenda más amplia y menos definida. b) La mayoría de los 
países donantes de ayuda, que la condicionan al buen gobierno, entienden éste como un tipo de ejercicio del poder que garantiza el crecimiento económico, la democracia pluripartidista, la economía de mercado, el respeto a los DERECHOS HUMANOS, la reducción del gasto militar y, en algunos casos, la equidad socioeconómica. c) Por su parte, el PNUD (Programa de Naciones Unidas para el Desarrollo) lo contempla con claves más ambiciosas, que guardan coherencia con su concepto del Desarrollo Humano. El pNud interpreta el gobierno (governance) de un país como el ejercicio de la autoridad económica, política y administrativa para manejar los asuntos de un país en todos los niveles a fin de que el Estado promueva la cohesión social, la integración y el bienestar de su población. Por tanto, el buen gobierno requiere la PARTICIPACION pública, para asegurar que las prioridades políticas, sociales y económicas estén basadas en un amplio consenso social, así como que las poblaciones más pobres y más vulnerables puedan incidir directamente en el proceso político de toma de decisiones. El PNuD dispone de un programa de buen gobierno que se centra en las instituciones de gobierno, la gestión de los sectores públicos y privados, la descentralización, las organizaciones de la sociedad civil y los gobiernos de países en transición a la economía de mercado. En definitiva, la concepción del buen gobierno delpnudes más amplia que otras, teniendo en cuenta elementos como los factores culturales, las particularidades nacionales, los liderazgos y la responsabilidad política, los procesos de participación social, así como la construcción de CAPACIDADES. d) Por último, diferentes sectores y autores critican la noción de buen gobierno por la subjetividad que encierra la definición de qué países lo cumplen y cuáles no; así como, sobre todo, por entender que éste y otros criterios de condicionalidad política de la ayuda representan una violación de la soberanía de los países receptores. En otras palabras, lo ven como un mecanismo encubierto de los países occidentales para perpetuar su control político sobre los países pobres. Algunos autores añaden que la condicionalidad del buen gobierno se emplea como un argumento más para justificar los recortes de la ayuda internacional. En general, estos críticos defienden que el buen gobierno debería interpretarse más bien como la práctica de aquellos gobiernos que trata de maximizar los beneficios sociales de sus políticas. 


\begin{tabular}{|c|c|c|}
\hline \multicolumn{3}{|c|}{ CONCEPTOS DE BUEN GOBIERNO DE DIVERSAS INSTITUCIONES } \\
\hline $\begin{array}{l}\text { ODA (Agencia Bilateral } \\
\text { del Gobierno Británico) }\end{array}$ & PNUD & Banco Mundial \\
\hline $\begin{array}{l}\text { Buen gobierno } \\
\text { Legitimidad } \\
\text { Rendición de cuentas (accoun- } \\
\text { tability) } \\
\text { Competencia (competence) } \\
\text { Derechos humanos/ley }\end{array}$ & $\begin{array}{l}\text { Buen Gobierno } \\
\text { Legitimidad política } \\
\text { Libertad de asociación y parti- } \\
\text { cipación } \\
\text { Sistema judicial justo y fiable } \\
\text { Rendición de cuentas adminis- } \\
\text { trativa (y financiera) } \\
\text { Libertad de información y ex- } \\
\text { presión } \\
\text { Gestión del sector público efi- } \\
\text { ciente y eficaz } \\
\text { Cooperación con instituciones } \\
\text { de la sociedad civil }\end{array}$ & $\begin{array}{l}\text { Buen Gobierno } \\
\text { Gestión política transparente y } \\
\text { previsible } \\
\text { Administración profesional } \\
\text { Poder ejecutivo que rinda } \\
\text { cuentas } \\
\text { Sociedad civil fuerte y partici- } \\
\text { pativa } \\
\text { Imperio de la ley }\end{array}$ \\
\hline
\end{tabular}

Fuente: Minogue (1998), con base en ODA (1993), UNDP (1995) y World Bank (1994).

Un tema estrechamente relacionado con el del buen gobierno y que recientemente ha comenzado a merecer atención en los estudios sobre el desarrollo es el de la corrupción (Third World Quarterly, 1999). Como recoge Minogue (1998: 9-10), ésta recibe explicaciones diversas desde diferentes posiciones teóricas. a) Algunos autores afirman que la raíz de la corrupción se encuentra en la dominación del Estado sobre la sociedad, por lo que reduciendo aquél y haciéndolo más eficiente disminuiría el problema. No obstante, dicen, su eliminación a largo plazo sólo se puede asegurar con la existencia de una democracia real, más que meramente formal. b) Otros autores hacen hincapié en que las transiciones rápidas hacia la economía de mercado propician la aparición y auge de la corrupción, debido al fortalecimiento e institucionalización de las redes de clientelismo. c) También hay quienes estiman que la corrupción es necesaria y beneficiosa cuando los mecanismos administrativos y económicos para el reparto de los recursos son defectuosos, contextos en los que el desarrollo político se lleva a cabo mediante instituciones clientelísticas. En este sentido, también se ha señalado que la corrupción ha sido tolerada por muchos gobiernos como una forma complementaria de ingresos para los funcionarios con el fin de retener su apoyo político en un contexto en el que sus sueldos han permanecido congelados por las restricciones presupuestarias impuestas por los programas de ajuste estructural. Otro aspecto en boga, vinculado al buen gobierno, es el de la descentralización, entendida de dos formas: a) la descentralización territorial, mediante la transferencia desde el centro hacia

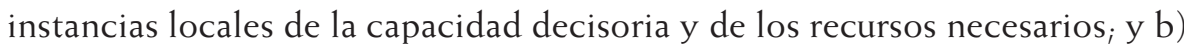
la "desconcentración" del poder político dentro del Estado hacia instancias inferiores, siguiendo el principio de subsidiariedad. La descentralización en los países en desarrollo ha recibido una atención creciente en las agendas de las agencias y gobiernos donantes, al entenderse que mejora la eficacia en la provisión de servicios sociales a la población. Como apunta Davies (1994:54), 
las políticas ejecutadas desde el gobierno central pueden resultar poco ajustadas a las situaciones locales específicas, sobre todo en países muy extensos. Ahora bien, dado que las instituciones locales (municipios) suelen carecer en los países en desarrollo de los recursos técnicos y humanos necesarios, en su opinión deberían ser las instituciones intermedias (distritos, comarcas) las beneficiarias de la descentralización, por cuanto pueden combinar la cercanía a los problemas y recursos locales con la necesaria planificación a escala nacional". 
ANEXO N. 2

UNIDADES ADMINISTRATIVAS ESPECIALES

\begin{tabular}{|c|c|c|}
\hline ENTIDAD & NORMA & ALCANCE DE LA NORMA \\
\hline $\begin{array}{c}\text { Agencia Nacional de Defensa } \\
\text { Jurídica del Estado }\end{array}$ & $\begin{array}{c}\text { Parágrafo del artículo 5 de la Ley } \\
\text { 1444 de 2011 } \\
\text { Decreto 4085 de 2011 }\end{array}$ & Creada \\
\hline $\begin{array}{c}\text { Agencia Colombiana para la } \\
\text { Reintegración de Personas }\end{array}$ & Decreto 4138 de 2011 & Creada \\
\hline $\begin{array}{c}\text { Agencia Presidencial para la } \\
\text { Cooperación Internacional }\end{array}$ & Decreto 4152 de 2011 \\
\hline $\begin{array}{c}\text { Agencia Nacional para la } \\
\text { Superación de la Pobreza } \\
\text { Extrema }\end{array}$ & Decreto 4160 de 2011 y \\
\hline $\begin{array}{c}\text { Agencia Nacional del Espectro } \\
\text { Agencia Nacional de } \\
\text { Contratación Pública - }\end{array}$ & Decreto 4169 de 2011 & Modifica la Naturaleza Jurídica \\
\hline $\begin{array}{c}\text { Colombia Compra Eficiente } \\
\text { Agencia del Inspector } \\
\text { General de Tributos, Rentas y } \\
\text { Contribuciones Parafiscales }\end{array}$ & Decreto 4173 de 2011 de 2011 & Creada \\
\hline $\begin{array}{c}\text { Agencia Nacional de Seguridad } \\
\text { Vial }\end{array}$ & Ley 1702 de 2013 & Creada \\
\hline
\end{tabular}

\section{AGENCIAS ESTATALES DE NATURALEZA ESPECIAL}

\begin{tabular}{|c|c|c|}
\hline ENTIDAD & NORMA & ALCANCE DE LA NORMA \\
\hline Agencia Nacional de Minería & Decreto 4134 de 2011 & Cambia la Naturaleza Jurídica \\
\hline $\begin{array}{c}\text { Agencia Nacional de } \\
\text { Hidrocarburos }\end{array}$ & Decreto 4137 de 2011 & $\begin{array}{c}\text { Modifica la Naturaleza Jurídica y } \\
\text { cambia la denominación }\end{array}$ \\
\hline $\begin{array}{c}\text { Agencia Nacional de } \\
\text { Infraestructura }\end{array}$ & Decreto 4165 de 2011 & Creada \\
\hline $\begin{array}{c}\text { Autoridad Nacional de } \\
\text { Televisión }\end{array}$ & Ley 1507 de 2012 & \\
\hline
\end{tabular}

